\title{
Development of Microwave-Assisted Sulfonated Glucose Catalyst for Biodiesel Production from Palm Fatty Acid Distillate (PFAD)
}

\author{
Nur Nazlina Saimon, Mazura Jusoh, Norzita Ngadi, Zaki Yamani Zakaria* \\ School of Chemical \& Energy Engineering, Faculty of Engineering, Universiti Teknologi Malaysia, \\ Skudai 81310, Johor, Malaysia.
}

Received: 22 $2^{\text {nd }}$ March 2021; Revised: 14th June 2021; Accepted: 15 th June 2021

Available online: 23rd June 2021; Published regularly: September 2021

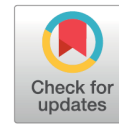

\begin{abstract}
Microwave-heating method for catalyst preparation has been utilized recently due to its shorter operation time compared to the conventional method. Glucose, a renewable carbon source can be partially carbonized and sulfonated via microwave heating which could result in highly potential heterogeneous carbon-based acid catalyst. In this study, the impacts of the carbonization and sulfonation parameters during the catalyst preparation were investigated. Catalysts prepared were characterized using Fourier Transform Infrared Spectroscopy (FTIR), Field Emission Scanning Electron Microscopy (FESEM), X-Ray Diffraction (XRD), Brunauer-Emmet-Teller (BET), and Temperature Programmed Desorption-Ammonia (TPD- $\mathrm{NH}_{3}$ ). Analysis of the carbonization screening process discovered that the best incomplete carbonized glucose (ICG) prepared was at 20 minutes, $20 \mathrm{~g}$ of $\mathrm{D}(+)$-glucose with medium microwave power level (400W) which exhibited the highest percentage yield (91.41\%) of fatty acid methyl ester (FAME). The total surface area and acid site density obtained were $16.94 \mathrm{~m}^{2} / \mathrm{g}$ and $25.65 \mathrm{mmol} / \mathrm{g}$, respectively. Regeneration test was further carried out and succeeded to achieve 6 cycles. The highest turnover frequency (TOF) of the sulfonated catalyst was methyl palmitate, $25.214 \times 10^{-3} \mathrm{~s}^{-1}$ compared to other component of the methyl ester. Kinetic study was developed throughout the esterification process and activation energy from the forward and reverse reaction was $3.36 \mathrm{~kJ} / \mathrm{mol}$ and $11.96 \mathrm{~kJ} / \mathrm{mol}$, respectively.
\end{abstract}

Copyright (C 2021 by Authors, Published by BCREC Group. This is an open access article under the CC BY-SA License (https://creativecommons.org/licenses/by-sa/4.0).

Keywords: Sulfonated glucose; Microwave-assisted; Palm Fatty Acid Distillate; Characterization; Turnover Frequency; Kinetic Study

How to Cite: N.N. Saimon, M. Jusoh, N. Ngadi, Z.Y. Zakaria (2021). Development of Microwave-Assisted Sulfonated Glucose Catalyst for Biodiesel Production from Palm Fatty Acid Distillate (PFAD). Bulletin of Chemical Reaction Engineering \& Catalysis, 16(3), 601-622 (doi:10.9767/bcrec.16.3.10520.601-622)

Permalink/DOI: https://doi.org/10.9767/bcrec.16.3.10520.601-622

\section{Introduction}

Major energy resource in the world has always been fossil fuels. However, over consumption of the fossil fuels raised several issues including the energy crisis due to serious environmental problem by emissions of hazardous gaseous [1] as well as the gradual reduction of fossil

\footnotetext{
* Corresponding Author.

Email: zakiyamani@utm.my (Z.Y. Zakaria);

Telp: +607-5335553
}

fuel resources [2]. In order to minimize the risks mentioned, alternative fuels have continuously been developed to lower down the usage of the fossil fuel. Biodiesel, an alternative fuel scientifically acknowledged as fatty acid methyl esters, can be synthesized from various renewable resources such as animal fats [3], vegetable oils [4], waste cooking oil [5] and by-product from oil refinery [6]. Esterification or transesterification is the method used to produce biodiesel. Basical- 
ly these two reactions requires homogeneous acid or base catalyst [7].

Sulfuric acid $\left(\mathrm{H}_{2} \mathrm{SO}_{4}\right)$ is the common acid catalyst used in biodiesel industry [8] due to its capability to esterify and transesterify simultaneously [9]. However, the utilization of $\mathrm{H}_{2} \mathrm{SO}_{4}$ creates corrosion and pollution problems [10]. Sodium hydroxide $(\mathrm{NaOH})$ and potassium hydroxide $(\mathrm{KOH})$ on the other hand are the common heterogeneous base catalyst used in industries [11]. However, these kind of base catalyst generates higher cost of post-treatment for the purification of the waste [12]. Meanwhile, heterogeneous acid catalyst promotes efficiency in economical and greener catalyst since lots of the raw material used is abundantly available and capable to esterify feedstock with high free fatty acid (FFA) content [13]. The preparation of certain heterogeneous acid catalysts such as zirconia-supported tungstated [14], zeolites [15] and $\gamma-\mathrm{Al}_{2} \mathrm{O}_{3}$ [16] are practically complicated towards application in industry [17]. In fact, the stability of the catalyst is quite poor with low value of acid density [18]. Thus utilization of raw materials from carbon-based catalysts offers high performance, easy preparation and high efficiency in esterifying high FFA feedstock.

Carbon-based materials such as $\mathrm{D}(+)$ Glucose can be obtained at a very cheap price and it is renewable as it is able to be generated from many resources such as oil palm frond juice [19]. It has been used as heterogeneous acid catalyst for biodiesel production by Lokman and colleagues, however the catalyst was conventionally prepared [20]. Conventional heating method is the most adopted technique in past studies because of the smooth heating due to gradual transfer of the heat accumulated around the surface of the object to the interior as shown in Figure 1. Even though conventional heating is the common method used in heating process, it consumes high amount of time and energy. Microwave (MW) on the other hand is much more effective because the sys-
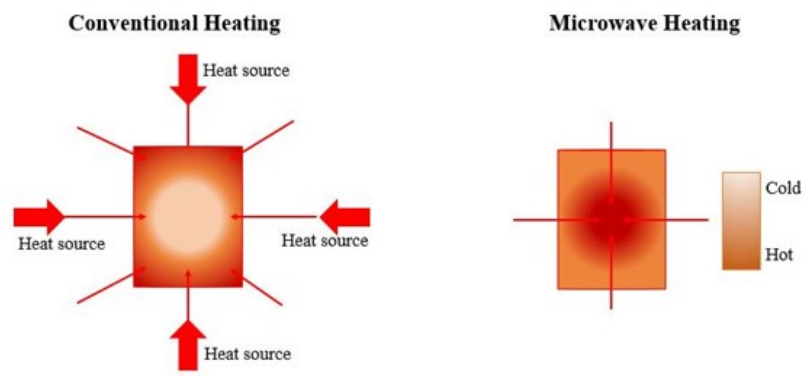

Figure 1. Conventional and microwave induced heating pattern. tem uses thermal radiation with sensational penetrability. In transesterification reaction context, MW radiation stimulates the ion movement and molecular motions of the oils, methanol and catalyst without altering their molecular structure [18]. MW radiation has been proven to shorten the heating time and improve the heating rate. Ning and Niu produced using bamboo-based acid catalyst prepared via MW heating and they successfully shortened the duration of sulfonation to 10 minutes providing $97.31 \%$ conversion of oleic acid [18]. In another study, Yu and colleague prepared sulfonated powder coal heterogeneous acid catalyst in just 5 minutes at temperature of $75{ }^{\circ} \mathrm{C}$ and obtained $98.1 \%$ of esterification efficiency from oleic acid [21].

Previous studies mostly had only investigated the length of time taken for respective work using MW and not on the overall specification of the MW itself. In this study, catalyst screenings were carried out to prepare the best performing incomplete carbonized glucose (ICG) followed by MW assisted sulfonation. Several parameters were taken into account in the catalyst synthesis process which include heating time (min), weight of $\mathrm{D}(+)$-glucose $(\mathrm{g})$, and microwave power level. Catalyst characterizations were conducted to determine the properties of the sulfonated glucose in catalyzing the esterification reaction of palm fatty acid distillate (PFAD) with methanol which include elemental analysis, Fourier Transform Infrared Spectroscopy (FTIR), X-Ray Diffraction (XRD), Field Emission Scanning Electron Microscopy (FESEM), Brunauer-Emmet-Teller (BET) as well as Temperature Programmed DesorptionAmmonia (TPD- $\mathrm{NH}_{3}$ ). One Factor at A Time (OFAT) method was used to find the best range of parameters for the carbonization process. Optimization was then conducted for sulfonation process to determine the optimum condition for the sulfonated glucose. In addition, sulfonated catalyst regeneration test as well as the turnover frequency (TOF) was also further carried out and calculated. The TOF of the sulfonated catalyst was calculated as the rate of methyl ester molecules produced per second per surface area of the sulfonated catalyst. The kinetic study of the esterification of PFAD and methanol using prepared catalyst was also derived in this study.

\section{Materials and Methods}

\subsection{Materials}

$\mathrm{D}(+)$-glucose (QRec (Asia) Sdn. Bhd.) and $\mathrm{H}_{2} \mathrm{SO}_{4}$ (J.T. Baker, US) were used for sulfonat- 
ed catalyst preparation. PFAD (Mewaholeo Industries Sdn. Bhd., Pasir Gudang, Malaysia) and methanol (Merck) on the other hand were used for catalytic reaction. Standard for methyl esters, such as: methyl linoleate, methyl myristate, methyl oleate, methyl palmitate as well as methyl stearate (Sigma-Aldrich), were used for GC analysis. All analytical grade products for all chemicals required no further purification. Equipment employed for sulfonated catalyst preparation was Microwave brand SHARP R213CST.

\subsection{Catalyst Preparation}

The catalyst preparation involved two stages which were the carbonization as well as sul-

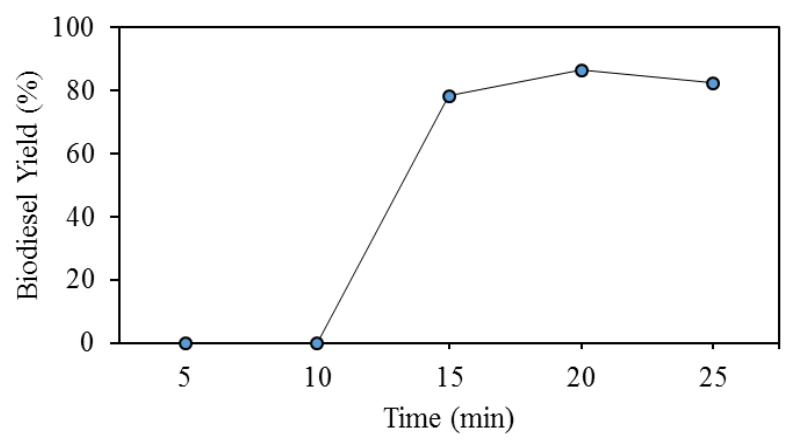

Figure 2. Effect of $\mathrm{D}(+)$-glucose carbonization heating time versus \% FAME Yield. During carbonization process, weight of $\mathrm{D}(+)$-glucose and microwave power level was set constant at $20 \mathrm{~g}$ and Medium Power Level $400 \mathrm{~W}$, respectively. Esterification reaction was run at $75{ }^{\circ} \mathrm{C}$ reaction temperature; $2.5 \mathrm{wt} \%$ catalyst loading; 10:1 molar ratio of methanol to PFAD; 2 hours of reaction time.

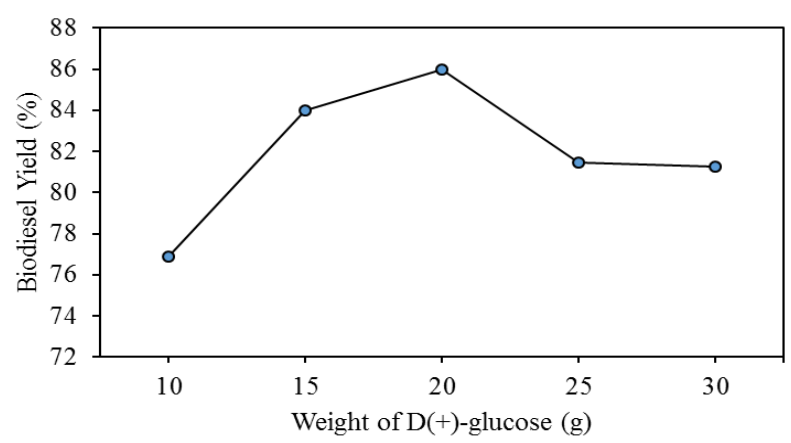

Figure 3. Effect of $\mathrm{D}(+)$-glucose carbonization weight versus \% FAME Yield. During carbonization process, heating time and microwave power level was set constant at 20 minutes and Medium Power Level $400 \mathrm{~W}$, respectively. Esterification reaction was run at $75^{\circ} \mathrm{C}$ reaction temperature; $2.5 \mathrm{wt} \%$ catalyst loading; 10:1 molar ratio of methanol to PFAD; 2 hours of reaction time. fonation processes. One Factor at A Time (OFAT) method was applied for carbonization since there was no clear basis of which parameter will be optimum for carbonizing the $\mathrm{D}(+)$ glucose. The results of the OFAT of the carbonization are graphically presented through Figure 2, Figure 3 and Figure 4. The sulfonation process parameters on the other hand were based on the previous study by Lokman and colleagues [20]. Carbonization parameters including mass of $\mathrm{D}(+)$-glucose $(\mathrm{g})$ at $10,15,20$, 25 , and $30 \mathrm{~g}$, heating time (min) at 5, 10, 15, 20 , and $25 \mathrm{~min}$, as well as microwave power level $(\mathrm{W})$ at low $(80 \mathrm{~W})$, medium low $(240 \mathrm{~W})$, medium $(400 \mathrm{~W})$, medium high $(560 \mathrm{~W})$, and high $(720 \mathrm{~W})$ were investigated and screened to provide the best range. Specific weights of $\mathrm{D}(+)$-glucose powder was melted through heating process in a microwave at given heating time (min). After the ICG was produced, it was then crushed and sieved to $0.5-1.0 \mathrm{~mm}$ particle size. $4 \mathrm{~g}$ of the crushed ICG $\left(50^{\circ} \mathrm{C}\right)$ was added with $100 \mathrm{~mL}$ of $98 \% \mathrm{H}_{2} \mathrm{SO}_{4}$ and stirred at 500 rpm for 5 minutes consecutively. The mixture was then heated inside a microwave at medium power level for sulfonation process for 7 minutes. The sulfonated catalyst was labelled as $\mathrm{SO}_{3} \mathrm{H} / \mathrm{ICG}$. The mixture was then filtered and black precipitate was collected. This was followed by a washing process using hot distilled water at $85^{\circ} \mathrm{C}$ to remove impurities contained in the mixture until the filtrate became a clear solution. Finally, the sulfonated catalyst was dried in an oven at $80{ }^{\circ} \mathrm{C}$ for 5 hours to remove the remaining moisture.

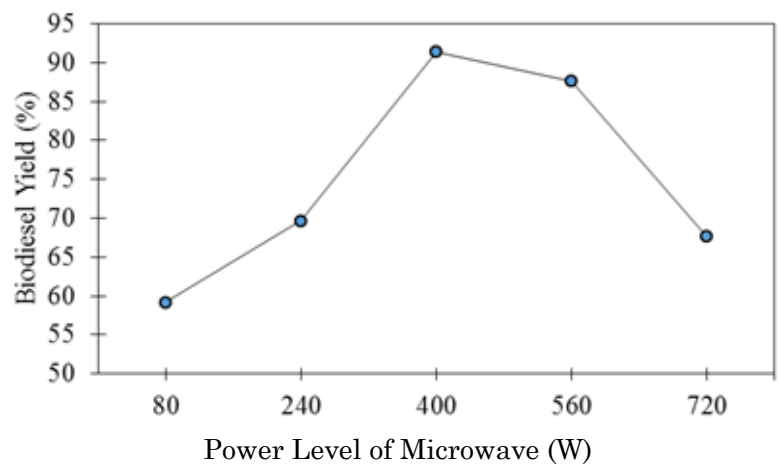

Figure 4. Effect of carbonization power level versus \% FAME Yield. During carbonization process, weight of $\mathrm{D}(+)$-glucose and heating time was set constant at $20 \mathrm{~g}$ and 20 minutes, respectively. Esterification reaction was run at $75{ }^{\circ} \mathrm{C}$ reaction temperature; 2.5 wt\% catalyst loading; 10:1 molar ratio of methanol to PFAD; 2 hours of reaction time. 


\subsection{Sulfonated Catalyst Characterization}

Elemental analysis, FESEM, FTIR, BET, $\mathrm{XRD}$, and TPD- $\mathrm{NH}_{3}$ were performed to characterize the sulfonated catalyst produced. Carbon, hydrogen, nitrogen, sulphur and oxygen contents were quantitatively measured by using Vario Micro, ELEMENTAR, AR, Germany. FESEM (Quanta FEI 400F) with 100, 1200, 2500, 5000, and 10000 magnifications was used to investigate the morphology of the $\mathrm{SO}_{3} \mathrm{H} / \mathrm{ICG}$ produced. The functional group of the sulfonated catalyst was determined through FTIR analysis using Shimadzu IRTracer-100. A hydraulic press was used to ground and pellet the catalyst in order to record the infrared spectrum in the range of $4000-500 \mathrm{~cm}^{-1}$. Scan range, $2 \theta$ from $2^{\circ}$ up to $60^{\circ}$ and $4^{\circ} \mathrm{min}^{-1}$ scanning rate was used to study the crystallinity of the sulfonated catalyst via XRD analysis (Bruker, D8 Advance). BET analysis on the other hand was mainly to determine the surface area of the prepared catalyst by degassing the catalyst at $150{ }^{\circ} \mathrm{C}$ under vacuum condition for about 3 hours using Micromeritics 3 Flex. Acid site density of the catalyst was measured through TPD- $\mathrm{NH}_{3}$ analysis by using Micromeritics AutoChem II.

\subsection{Fatty Acid Methyl Ester (FAME) Produc- tion}

In this study, fatty acid methyl ester (FAME) represents the biodiesel that was produced. Free fatty acid (FFA) of PFAD can be reduced through esterification process. PFAD was weighed based on molar ratio and properly heated at $65{ }^{\circ} \mathrm{C}$. Preheated PFAD was poured into a 3-neck round-bottom flask followed by the methanol and prepared catalyst. 10:1 molar ratio of $\mathrm{PFAD}$ and methanol was used while 2.5 wt $\%$ of sulfonated glucose loading was used for the esterification. The mixture was then refluxed to $75{ }^{\circ} \mathrm{C}$ for 120 minutes before being poured into a separating funnel and let settled for about 3 hours. FAME and water layer were then separated from the catalyst and the mass of the FAME produced from the esterification was weighed to calculate the FAME yield.

\subsection{Analysis of PFAD Methyl Ester}

The percentage yield of FAME was calculated using Equation 1. Acid-base titration method on the other hand was used to determine the percentage conversion of the PFAD. The $1 \mathrm{~mL}$ of FAME was taken out from the catalyst and $20 \mathrm{~mL}$ of the solvent (methanol) was added. The mixture was then vigorously shaken until it completely dissolved. 2-3 drops of phenolphthalein were added into the flask and titrated with standard $\mathrm{KOH}$ solution until the first permanent pink color showed up. The formula to calculate the percentage of methyl ester yield is defined by Eqs. (1)-(3).

$$
\begin{aligned}
& \text { Yield }(\%)=\frac{\text { Weight of experimental FAME }(g) \times 100}{\text { Weight of theoretical FAME }(g)} \\
& \text { Acid Value }=\frac{N \times M W K O H \times \text { Volume of KOH titrate used }(m L)}{\text { Mass of FAME }(g)}
\end{aligned}
$$

where, $N$ is referring to the normality of $\mathrm{KOH}$ used and $M W$ indicating the molecular weight of $\mathrm{KOH}$ which is $56.11 \mathrm{~g} / \mathrm{mol}$.

$$
\text { Conversion }(\%)=\frac{(\text { Acid value of PFAD }- \text { Acid value of sample })}{\text { Acid value of PFAD }} \times 100 \%
$$

\subsection{Kinetic Study}

For kinetic study, 3 parameters were involved including temperature of esterification (65, 75, and $85^{\circ} \mathrm{C}$ ), molar ratio of oil to PFAD (5:1, 10:1 and 15:1) as well as catalyst loading (1.0, 2.5 and 4.0). Eleven readings were taken for each experimental run for each 12 minutes gap. The derivation of the kinetic study in order to obtain the value of reaction rate, activation energy and pre-exponential factor were described in following equations. The esterification of PFAD and methanol with the presence of catalyst $\mathrm{SO}_{3} \mathrm{H} / \mathrm{ICG}$ is shown as follow:

$$
\begin{aligned}
& \mathrm{R}_{1} \mathrm{COOH}+\mathrm{MeOH} \stackrel{k_{1}, k_{2}}{\rightleftharpoons} R_{1} \mathrm{COOCH}_{3}+\mathrm{H}_{2} \mathrm{O} \\
& A+B \stackrel{k_{1}, k_{2}}{\rightleftharpoons} \mathrm{C}+D
\end{aligned}
$$

The rate of reaction rate for forward as well as reverse reaction can be symbolized as $\mathrm{k}_{1}$ and $\mathrm{k}_{2}$, respectively. The kinetic model was developed based on several assumptions: (1) The mass transfer of the system is ignored; (2) The forward and reverse reactions were following pseudo second order reaction in liquid phase; (3) Rate of reaction of non-catalyzed reactions are ignored [22]. The reaction rates of the esterification of PFAD catalyzed by $\mathrm{SO}_{3} \mathrm{H} / \mathrm{ICG}$ based on the above assumptions, can be written as follow:

$$
r_{A}=-\frac{d[A]}{d t}=k_{1}[A][B]-k_{2}[C][D]
$$

Where $r_{A}$ is the rate of reaction for esterification process, $k_{1}$ is the reaction rate constant of forward $k_{2}$ is the reaction rate constant of reverse. $[\mathrm{A}],[\mathrm{B}],[\mathrm{C}]$, and $[\mathrm{D}]$ are the concentration of the PFAD, methanol and water at time $t$, respectively, meanwhile $t$ is reaction time in min. 
The initial concentration of $\mathrm{A}$ and $\mathrm{B}$ is basically different however, the amount $\mathrm{A}$ and $\mathrm{B}$ consumed is equivalent to $\mathrm{C}$ and $\mathrm{D}$ formed during the reaction. Assume $x$ as the conversion of the A at time $t$, thus the concentration of the reactants and products becomes as follows:

$$
\begin{aligned}
& {[A]=\left[A_{0}\right](1-x)} \\
& {[B]=\left[B_{0}\right]-x\left[A_{0}\right]} \\
& {[C]=[D]=x\left[A_{0}\right]}
\end{aligned}
$$

where, $\left[A_{0}\right]$ and $\left[B_{0}\right]$ are the initial concentration of PFAD and methanol respectively, and $\mathrm{x}$ is the conversion of the PFAD. Equations (7), (8) and (9) were substituted in to Equation (6) and is simplified as follows:

$$
\begin{aligned}
& \begin{aligned}
-r_{A}=\left[A_{0}\right] \frac{d x}{d t}=k_{1}\left[A_{0}\right](1-x) \cdot\left(\left[B_{0}\right]-x\left[A_{0}\right]\right) \\
\quad-k_{2} x^{2}\left[A_{0}\right]^{2}
\end{aligned} \\
& \begin{aligned}
{\left[A_{0}\right] \frac{d x}{d t}=} & \left(k_{1}\left[A_{0}\right]-k_{1} x\left[A_{0}\right]\right) \cdot\left(\left[B_{0}\right]-x\left[A_{0}\right]\right) \\
& -k_{2} x^{2}\left[A_{0}\right]^{2}
\end{aligned} \\
& \begin{aligned}
{\left[A_{0}\right] \frac{d x}{d t}=} & k_{1}\left[A_{0}\left[B_{0}\right]-k_{1} x\left[A_{0}\right]^{2}-k_{1} x\left[A_{0}\right] B_{0}\right] \\
& +k_{1} x^{2}\left[A_{0}\right]^{2}-k_{2} x^{2}\left[A_{0}\right]^{2}
\end{aligned} \\
& \begin{aligned}
\frac{d x}{d t}= & k_{1}\left[B_{0}\right]-k_{1} x\left[A_{0}\right]-k_{1} x\left[B_{0}\right]+k_{1} x^{2}\left[A_{0}\right] \\
- & k_{2} x^{2}\left[A_{0}\right]
\end{aligned} \\
& \frac{d x}{d t}=k_{1}\left[A_{0}\right]\left(\left[\frac{\left[B_{0}\right]}{\left[\left[A_{0}\right]\right.}-x-\frac{x\left[B_{0}\right]}{\left[A_{0}\right]}+x^{2}-\frac{k_{2} x^{2}}{k_{1}}\right)\right.
\end{aligned}
$$

$\theta$ is introduced as the ratio of initial concentration of methanol to PFAD, while $K$ as the ratio of rate constant of forward to reverse reaction. $\theta$ and $K$ are substituted in to equation (14) and can be expressed as below:

$$
\begin{aligned}
& \frac{d x}{d t}=k_{1}\left[A_{0}\right]\left(\theta-x-x \theta+x^{2}-\frac{x^{2}}{K}\right) \\
& \frac{d x}{d t}=k_{1}\left[A_{0}\right]\left(x^{2}\left(1-\frac{1}{K}\right)-x(1+\theta)+\theta\right)
\end{aligned}
$$

$d x / d t$ is equal to 0 while the conversion of the PFAD is symbolized as $x_{e}$ when equilibrium reach in a reaction.

$$
\begin{aligned}
& 0=x_{e}^{2}\left(1-\frac{1}{K}\right)-x_{e}(1+\theta)+\theta \\
& x_{e}^{2}\left(1-\frac{1}{K}\right)=x_{e}(1+\theta)-\theta \\
& x_{e}^{2}-\frac{x_{e}^{2}}{K}=x_{e}+x_{e} \theta-\theta \\
& \frac{x_{e}^{2}}{K}=x_{e}^{2}-x_{e}-x_{e} \theta+\theta \\
& K=\frac{x_{e}^{2}}{x_{e}^{2}-x_{e}-x_{e} \theta+\theta}
\end{aligned}
$$

Equation (21) can be simplified as below:

$$
K=\frac{x_{e}^{2}}{\left(1-x_{e}\right)\left(\theta-x_{e}\right)}
$$

Integration of Equation (16) can be expressed as follow:

$$
\int_{0}^{x} \frac{d x}{\left(x^{2}\left(1-\frac{1}{K}\right)-x(1+\theta)+\theta\right)}=\int_{0}^{t} k_{1}\left[A_{0}\right] d t
$$

Two parameters are introduced, $a=1-1 / K$ and $b=\sqrt{\left(1+\theta^{2}\right)-4 \mathrm{a} \theta}$

Both $\mathrm{a}$ and $\mathrm{b}$ are substituted into equation (23) and can be expressed as follow:

$$
\begin{aligned}
& \int_{0}^{x} \frac{d x}{\left(\left(x+\frac{b-\theta-1}{2 a}\right)\left(x-\frac{b+\theta+1}{2 a}\right)\right)}=\int_{0}^{t} k_{1}\left[A_{0}\right] d t \\
& \ln \left(\frac{x+\frac{b+1+\theta}{2 \mathrm{a}}}{x-\frac{b-1-\theta}{2 \mathrm{a}}}\right)=-\frac{b k_{1}\left[A_{0}\right] t}{\mathrm{a}}+\ln \left(\frac{1+\theta+b}{1+\theta-b}\right)
\end{aligned}
$$

Equation (25) can be plotted based on $y=m x+c$, and the respective value for activation energy, $E_{a}$ and pre-exponential factor, $A$.

\section{Results and Discussion}

\subsection{Elemental Analysis of D(+)-Glucose}

The CHNS content of $\mathrm{D}(+)$-glucose, ICG and sulfonated glucose prepared by MW assisted heating method are tabulated in Table 1 . The raw $\mathrm{D}(+)$-glucose was mostly composed of 36.7 wt\% of carbon (C), $6.9 \mathrm{wt} \%$ of hydrogen $(\mathrm{H}), 0.1$ $\mathrm{wt} \%$ of nitrogen $(\mathrm{N})$ and $56.0 \mathrm{wt} \%$ of oxygen

Table 1 . The C, H, N, S, O content of ICG, CCG and catalyst.

\begin{tabular}{lcccccc}
\hline Sample & $\mathrm{C} \mathrm{( \% )}$ & $\mathrm{H}(\%)$ & $\mathrm{N}(\%)$ & $\mathrm{S}(\%)$ & $\mathrm{O}(\%)$ & Ash(\%) \\
\hline D(+)-glucose & 36.7 & 6.9 & 0.1 & 0 & 56.0 & 0.0 \\
ICG & 67.3 & 4.8 & 0.5 & 0 & 18.1 & 9.3 \\
Sulfonated Glucose Catalyst & 53.9 & 4.3 & 0.4 & 6.9 & 23.6 & 10.8 \\
\hline
\end{tabular}


(O). After carbonization, the $\mathrm{C}$ content obviously increased to $67.3 \mathrm{wt} \%$. Contents of $\mathrm{H}$ and $\mathrm{O}$ however, were reduced to $4.8 \mathrm{wt} \%$ and 18.1 wt\%, respectively. This is mainly due to the effect of dehydration in the MW heating system [23] during the carbonization process. The increment of the $\mathrm{C}$ content is due to the decomposition of the glucose at high temperature at this case it was being heated at $400 \mathrm{~W}$. At high temperature, decomposition of glucose occur and release non-carbonaceous materials in the form of liquid or gaseous substances thereby leaving behind a rigid carbon skeleton thus lead to the high carbon content [24]. The reduction of $\mathrm{H}$ and $\mathrm{O}$ contents can be attributed to the dehydration and deoxygenation effect as well as possible volatilation some of the molecule during the carbonization heating [25]. Contents of $\mathrm{C}$ and $\mathrm{H}$ were decreased to $53.9 \%$ and $4.3 \%$, respectively after the catalyst went through the sulfonation process. $\mathrm{O}$ and $\mathrm{S}$ on the other hand were visibly increased due to the dominance of the sulfonic acid group's $\left(-\mathrm{SO}_{3} \mathrm{H}\right)$ attachment towards the surface of the catalyst. Sulphur (S) was not detected in the raw material, however, the sulfonation processes resulted in $\mathrm{S}$ content of $6.9 \mathrm{wt} \%$. This result was confirmed after the introduction of sulfuric acid during the sulfonation process of the ICG. Similar observations were also reported in the transformation of bamboo [18], palm empty fruit bunch, coconut meal residue, and coconut coir husk into solid acid catalysts [26]. Contrary to the direct and template methods of carbonization, the chemical method indicates a decreased in carbon and hydrogen contents from 64.9 to $57.5 \%$ and 3.7 to $1.1 \%$ with increased temperature of carbonization from 400 to $800{ }^{\circ} \mathrm{C}$, respectively, while the oxygen content was enhanced from 30.3 to $40.9 \%$. These observations may be due to the combined effects of both the $\mathrm{H}_{3} \mathrm{PO}_{4}$ impregnation and high-temperature carbonization resulting in intense degradation, dehydration,

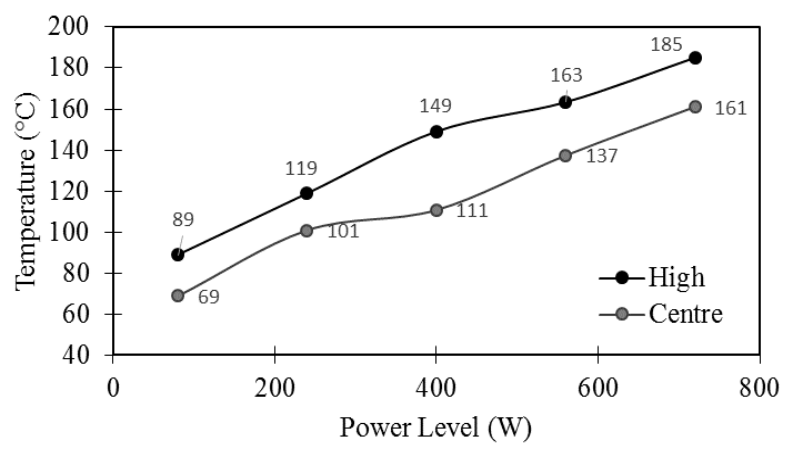

Figure 5. Catalyst temperature $\left({ }^{\circ} \mathrm{C}\right)$ and microwave power level (watt) correlation. and oxidation of the biomass material leading to the formation of more cross-links polycyclic aromatic carbon sheets [27]. A study from Umar et al. reported a reduction in $\mathrm{C}$ and $\mathrm{H}$ content after the sulfonation process of palm kernel shell (PC400S). The catalyst showed an increment of $\mathrm{O}$ and $\mathrm{S}$ contents as well [28]. This is in line with this study. The sulphur content generally increased after sulfonation indicating that the sulfonic acid group was successfully incorporated onto the carbon material [29].

\subsection{Characterization of Selected Sulfonated Glucose Catalyst}

Figure 2 represents the effect of catalyst synthesis heating time on FAME yield. The percentage of FAME yield increased when $\mathrm{D}(+)$-glucose was carbonized from 15 minutes to 20 minutes but dropped slightly when it was set to 25 minutes. ICG was not completely produced at 5 and 10 minutes since the color and structure of the glucose remained the same. Thus, esterification using incompletely formed ICG will generate lowest yield of methyl ester. Figure 3 on the other hand indicates the effect of $\mathrm{D}(+)$-glucose's weight on FAME yield percentage. The trend shows an increment towards FAME yield as the weight of $\mathrm{D}(+)$ glucose increases from $10 \mathrm{~g}$ to $20 \mathrm{~g}$ but reduces slightly as the weight escalates gradually to 30 g. $20 \mathrm{~g}$ of $\mathrm{D}(+)$-glucose was found to be the optimum weight for carbonization. As catalyst bulk mass increases in size, its total power absorption is known to asymptotically approach the power level of the microwave [30]. Thus, for large catalysts, the total power absorption shows strong oscillations with size.

Figure 4 however shows the effect of the MW power level towards the FAME yield. The microwave was provided with certain ranges of power level (watt). The trend is quite similar to Figure 3 since further increment of power level resulted in a rise of the FAME yield from $59.22 \%$ to $91.41 \%$ at medium power level. However, after a continuous increment of power level, a decrease of FAME yield occurred. Based on the screening result, it can be summed up that optimal carbonization was achieved at 20 minutes, $20 \mathrm{~g}$ of $\mathrm{D}(+)$-glucose and medium power level.

Figure 5 displays the distribution of high and center temperature of the catalysts provided in different power levels of microwave. The temperatures were determined by using a thermal imager (Fluke VT04A). The high temperature provided by the thermal imager is the highest spot inside the microwave that can be 
reached for specific power level. In this case, the highest temperature that can be achieved was $185^{\circ} \mathrm{C}$ for the highest power level used $(720 \mathrm{~W})$, while the highest temperature for the lowest power level $(80 \mathrm{~W})$ was only $89{ }^{\circ} \mathrm{C}$. Meanwhile the center temperature is given based on the temperature of the center spot inside the microwave. From the distribution of the temperature, it is clearly indicated that the sulfonated glucose heating could occur and take place even at lower temperature in a microwave instead of using higher temperature by conventional heating method. Based on Figure 5 , as the power level increased throughout this study, the further the penetration that is able to go through the surface thus increasing the temperature as well as the amplitude of transmitted wave within the glucose layer [31]. Figure 6 shows the temperature contour or map scale at high microwave power level $(720 \mathrm{~W})$. It is obvious that the distribution of the temperature was focused at the center where the catalyst was being heated. The microwave field of the multimode instruments was generally distributed in a chaotic manner. This is mostly due to the heating effect of penetration depth which raises the volume of incident wave covered deep into the catalyst layer [31]. Table 2 tabulates the catalysts randomly selected to be characterized. A, B, C, D and E were selected based on the highest and lowest yield percentage as well as the different microwave power levels during the carbonization of the glucose.

The crystallinity of the sulfonated glucose acid catalyst shown in Figure 7 was based on

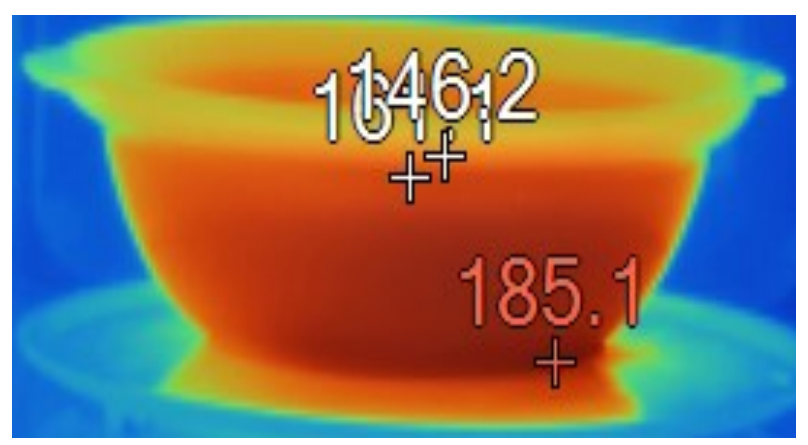

Figure 6. Temperature map scale at $720 \mathrm{~W}$ for the prepared catalyst.
XRD analysis. The pattern provides 2 peaks, a broad and a weak diffraction existing at $2 \theta$ of $2^{\circ}-10^{\circ}$ and $25^{\circ}-35^{\circ}$. At $2^{\circ}-10^{\circ}$, the graphitic $\mathrm{C}(002)$ plane is attributed for the amorphous carbon and shows both of the catalysts and precursor comprising considerably random fashion of aromatic carbon sheets [32]. C(101) plane on the other hand is basically attributed to the carbon's graphitic structure [33]. Both structures are crystalline, which indicates the glassy structure of the catalyst. The XRD pattern of catalyst A, B and D show the increment of intensity substantially between $2^{\circ}$ to $10^{\circ}$ compared to catalyst $\mathrm{C}$. These changes explain that the growing crystallinity of the catalyst is attributed to the carbonization factor using different power levels of the microwave. Catalyst $\mathrm{C}$ was carbonized by using low power level which is about $80 \mathrm{~W} .80 \mathrm{~W}$ is basically used for gentle defrosting, because the irradiation produced through low power level is relatively small and previous study showed that low power level only indicates low temperature which basically does not exceed the melting point of the $\mathrm{D}(+)$-glucose [34]. Klinbun et al. [31] proves that high power level is capable to penetrate deep inside the surface compared to low power
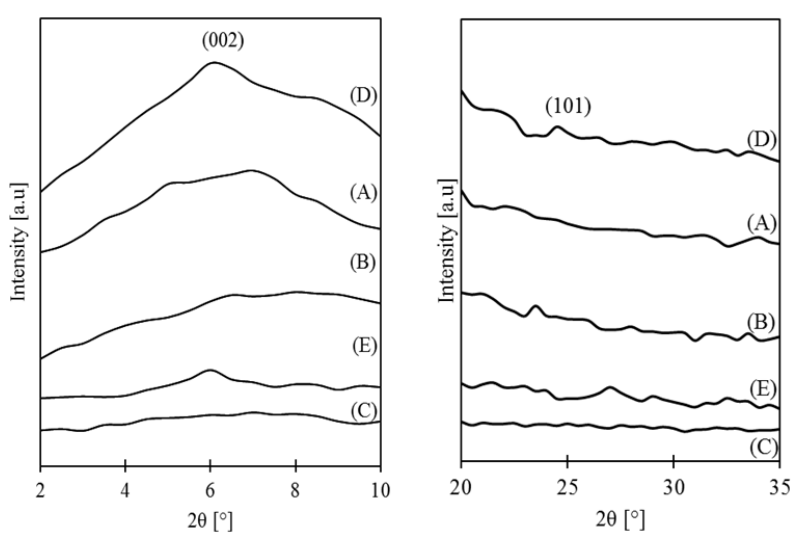

Figure 7. XRD Diffractogram of sulfonated glucose; A (20 g $\mathrm{D}(+)$-glucose; 15 minutes; Medium), B (30 g D(+)-glucose; 20 minutes; Medium), C (20 g D(+)-glucose; 20 minutes; Low), D (20 g D(+)-glucose; 20 minutes; Medi$\mathrm{um})$ and $\mathrm{E}(20 \mathrm{~g} \mathrm{D}(+)$-glucose; 20 minutes; Medium Low).

Table 2. Selected catalyst for characterization analysis.

\begin{tabular}{lccccc}
\hline ICG Preparation/Catalyst & $\mathrm{A}$ & $\mathrm{B}$ & $\mathrm{C}$ & $\mathrm{D}$ & $\mathrm{E}$ \\
\hline Weight D(+)-glucose (g) & 20 & 30 & 20 & 20 & 20 \\
Heating time (min) & 15 & 20 & 20 & 20 & 20 \\
\multirow{2}{*}{ Power level microwave } & Medium & Medium & Low & Medium & Medium low \\
& $(400 \mathrm{~W})$ & $(400 \mathrm{~W})$ & $(80 \mathrm{~W})$ & $(400 \mathrm{~W})$ & $(240 \mathrm{~W})$ \\
\hline
\end{tabular}


level which points to greater amplitude of wave transmittance within water layer.

The FTIR spectra demonstrate the functional group of sulfonated glucose at various conditions. Figure 8 shows the plotted IR spectra of sulfonated ICG catalyst prepared via microwave for catalyst $\mathrm{A}, \mathrm{B}, \mathrm{C}, \mathrm{D}$, and $\mathrm{E}$. In this study, the FTIR spectra of the catalysts prepared were observed and analyzed to confirm the presence of sulfonic, carboxylic and poly aromatic carbon characteristic bands. The capability of the amorphous carbon attached to the $-\mathrm{COOH}$ and $-\mathrm{OH}$ hydrophilic molecules is quite unique [33]. These kinds of molecules are basically provided with extra sites for $-\mathrm{SO}_{3} \mathrm{H}$ to be bonded with the catalyst. Peaks present at wave number around $1036.10 \mathrm{~cm}^{-1}$ for catalyst $\mathrm{C}$ and up to $1082.31 \mathrm{~cm}^{-1}$ for catalyst A were attributed to the $\mathrm{O}-\mathrm{S}-\mathrm{O}$ symmetric stretching modes. Another proof of sulfonic groups was confirmed by the presence of clear bands at $1166.82 \mathrm{~cm}^{-1}$ for $\mathrm{O}-\mathrm{S}-\mathrm{O}$ asymmetric stretching that indicates $-\mathrm{SO}_{3} \mathrm{H}$ group is covalently bonded to the poly aromatic carbon structure. The sharp peak at bands around $1500 \mathrm{~cm}^{-1}$ for all five catalysts was assigned to the aromatic ring $\mathrm{C}-\mathrm{C}$ stretching. Meanwhile, the peak at $1624.95 \mathrm{~cm}^{-1}$ was attributed to the $\mathrm{C}-\mathrm{O}$ stretching mode from $-\mathrm{COOH}$ group. Nakajima and Hara [35] found similar trends from the IR absorption of the sulfonated glucose acid catalyst. Lokman et al. [33] also reported the raw glucose before sulfonation process exhibited the same peak around 1000-1200 $\mathrm{cm}^{-1}$, however the intensity of the peak was weak mostly due to the effective adsorption of the IR towards the rearranged carbon frameworks from the thermal treatment. During the carbonization pro-

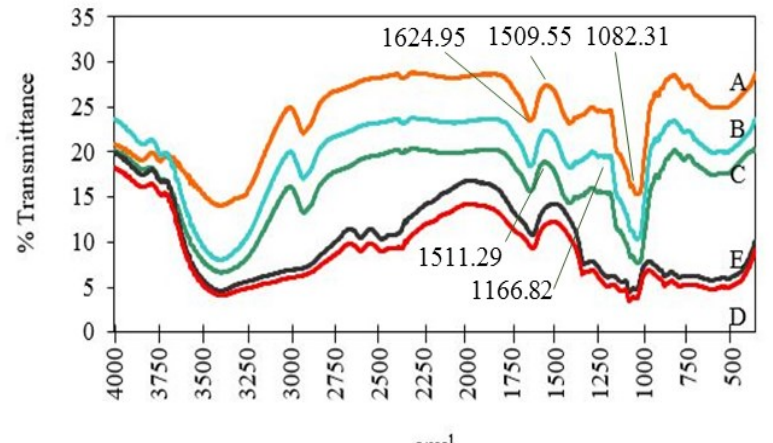

$\mathrm{cm}^{-1}$

Figure 8. IR Spectrum for sulfonated glucose of catalyst A (20 g D(+)-glucose; 15 minutes; Medium), B (30 g D(+)-glucose; 20 minutes; Medium), C (20 g D(+)-glucose; 20 minutes; Low), D (20 g D(+)-glucose; 20 minutes; Medium) and $\mathrm{E}(20 \mathrm{~g} \mathrm{D}(+)$-glucose; 20 minutes; Medium Low). cess, introduction of the $\mathrm{C}-\mathrm{O}-\mathrm{C}$ cleavage and dehydration of water molecules occurred and formed polycyclic aromatic carbon structure. The structure of the amorphous carbon material was also reported by Okamura and colleagues [36].

The morphology and microstructure of the catalyst prepared at different times of acid treatment were examined by FESEM. Figure 9 presents the FESEM micrographs of the sulfonated glucose prepared with different parameters. A, B, C, D and E are catalyst from different range of parameters including the weight of $\mathrm{D}(+)$-Glucose used (g), the heating time (min) and power level of microwave. The image denotes the diameter particles of the sulfonated glucose ranging from 10 to $200 \mu \mathrm{m}$ in sizes. The images of A, B and D were homogenously decorated with well dispersed particles. Lokman and colleagues proved that raw glucose exhibits a microstructure of mesoporous feature, an irregular as well as aggregate structure of the sulfonated glucose in micrometer dimension [20], which is quite similar to catalyst $\mathrm{A}, \mathrm{B}$ and D. Catalyst $\mathrm{C}$ and $\mathrm{E}$ on the other hand exhibited quite bulky, mossy type of surface. This is due to the different power level used during the carbonization process. Lower power level indicates lower intensity of the radiation towards the surface of the catalyst. Thus, bulky and mossy surface was established for lower power level. Dehydration condensation causes formation of polycyclic carbon sheets at low carbonization power level. At this stage, a huge number of oxygenated functional groups will be cut off to provide advantage for sulfonic acid group attachment. However, high power level of the microwave damages pile of the polycyclic aromatic carbon frames and creates a firm structure which is basically not preferred for active sites introduction. During the catalytic reactions of the sulfonated glucose at high power level, side reactions apparently take place on the surface of the catalyst. This reaction yields some carbonaceous residues that cover the active surfaces and block the pores thus deactivating the catalyst [37].

Through carbonization process, surface area of the catalyst will decompose thus reducing the particles size. Pores formation on the sulfonated glucose defines a high surface area values. Using low power level of microwave exhibited insignificant surface area $\left(2.03 \mathrm{~m}^{2} / \mathrm{g}\right)$ because of reasonably low heating provided to the incomplete carbonized glucose. Optimum power level and temperature of the microwave are necessary to provide decomposition of the structure and shrink the carbon bonding be- 


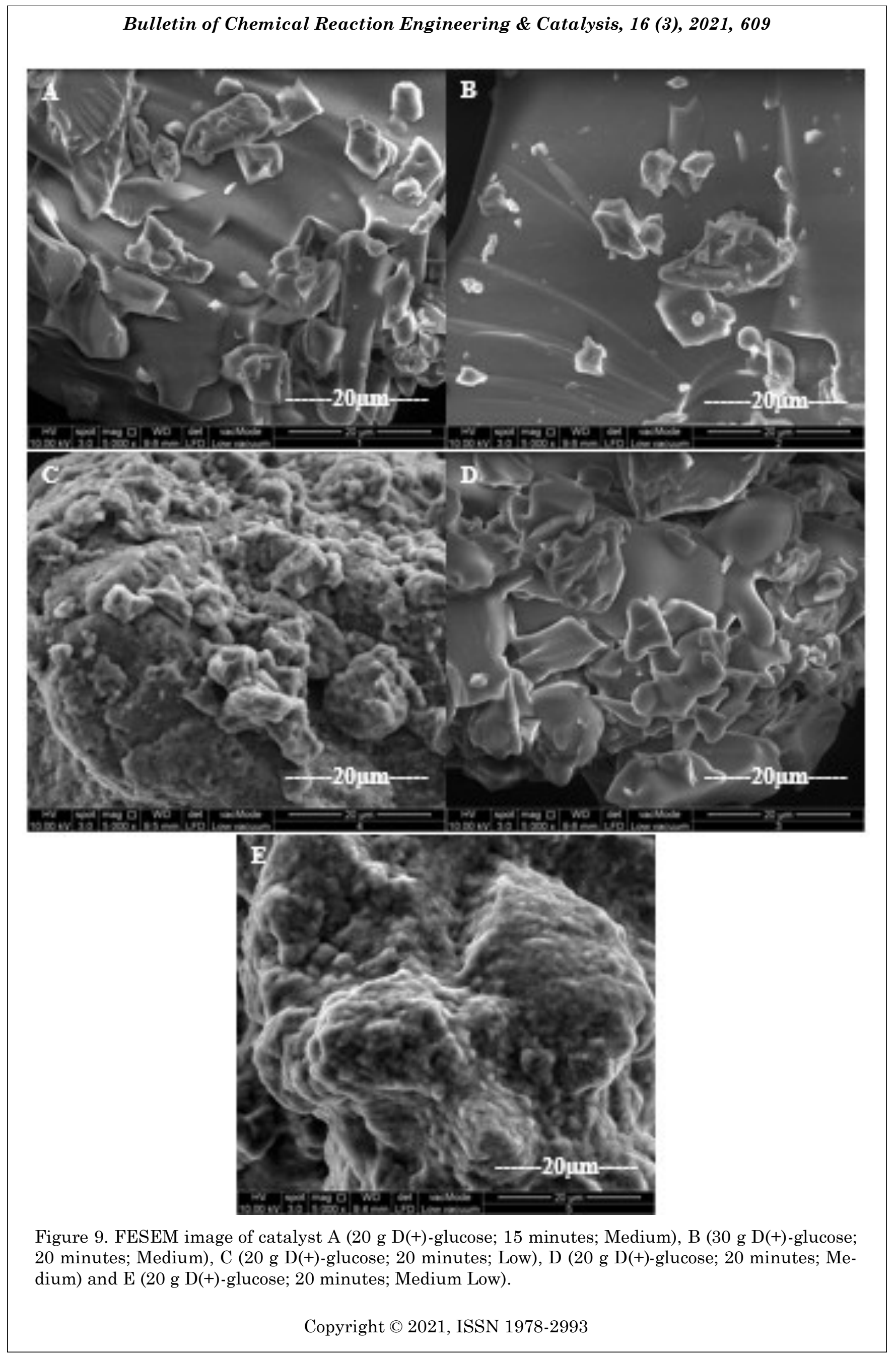


tween the particle thus expanding the pores formation [38].

For $\mathrm{C}$ and $\mathrm{E}$ catalysts, difference in the surface area was slightly observed basically due to the low rate of decomposition of the glucose and slow pores formation growth. To enhance the catalytic activity of the catalyst, a large surface area is essential. Increment of microwave power level reduces the acidity of the sulfonated glucose. Medium power level $(400 \mathrm{~W})$ of microwave was selected as an optimum carbonization of the glucose since it provided large surface area $\left(16.94 \mathrm{~m}^{2} / \mathrm{g}\right)$ and high acidity $(25.65$ $\mathrm{mmol} / \mathrm{g}$ ). The effect of heating time during the carbonization process is tabulated in Table 3. Surface area of the sulfonated glucose increased with the increment of the carbonization time from $9.32 \mathrm{~m}^{2} / \mathrm{g}$ to $16.94 \mathrm{~m}^{2} / \mathrm{g}$ for $15 \mathrm{~min}$ and $20 \mathrm{~min}$, respectively. $20 \mathrm{~min}$ of carbonization time validate with highest surface area and acidity of $16.94 \mathrm{~m}^{2} / \mathrm{g}$ and $25.65 \mathrm{mmol} / \mathrm{g}$, respectively.

Lou's group reported the catalytic activity of four different carbohydrate solid acid catalyst from cellulose, sucrose, $\mathrm{D}(+)$-glucose and starch for esterification process [39]. All preparation of catalyst was prepared conventionally and carbonisation was carried out at $400{ }^{\circ} \mathrm{C}$. The study reported that starch provided with highest catalytic activity with $95 \%$ of conversion followed by cellulose (88\%), sucrose $(80 \%)$ and $\mathrm{D}(+)$-Glucose $(76 \%)$. To achieve almost $95 \%$ of yield cellulose, sucrose and $\mathrm{D}(+)$-Glucose required 4 to $5 \mathrm{hr}$ compared with starch which required only $3 \mathrm{hr}$. XRD analysis for all catalysts showed amorphous carbon however the starch catalyst possesses the most favorable properties with largest surface area and average pore volume and pore sizes as well. With large number of the surface area $(7.2 \mathrm{~m} / \mathrm{g})$, average pore volume $\left(0.81 \mathrm{~cm}^{3} / \mathrm{g}\right)$ and pore size $(8.2 \mathrm{~nm})$ allowed reactants to access to the $\mathrm{SO}_{3} \mathrm{H}$ sites leading to the higher efficiency of the starch catalyst. Thus the starch possessed highest sulphur content and acid site density (1.83 $\mathrm{mmol} / \mathrm{g}$ ). The starch is the complex version of glucose, since the glucose was used as a catalyst in this current study, it still provide with highest value of surface area and acid site density compared with the $\mathrm{D}(+)$-Glucose catalyst produced conventionally.

Heating time plays an important role for carbonization due to the formation of polycyclic aromatic carbon sheets which basically occurs for certain duration [18]. Further increment of the heating time is insignificant once the polycyclic aromatic carbon sheets are formed. As proven from this study, the optimum carbonization duration reached was 20 minutes with $91.41 \%$ of FAME yield produced. After a prolonged duration, the FAME yield seems to be reduced to $82.41 \%$ at 25 minutes based on Figure 2. Hence, the most optimal heating time for carbonization process should be 20 minutes. The FAME yield of esterification of PFAD with methanol using the prepared catalyst was a slightly lower than the conventional FAME yield which was $92.3 \%$ [20], however the heating time and energy are more economically viable for the catalyst prepared in this study. To date, various acid catalysts from numerous carbon based materials have been used. Corn straw was used by Liu and colleagues and they obtained the optimal carbonization duration of 1 hour via conventional method [40]. Touhami et al. [41], however, used rice husk as a heterogeneous acid catalyst and established 30 minutes for the optimal carbonization duration using MW heating method. This study is comparable to previous research done by Touhami et al. and provides better alternative for carbonization process in shorter time yet capable to produce high yield of FAME.

Distribution of the acid sites density of the sulfonated glucose by using TPD- $\mathrm{NH}_{3}$ is depicted in Figure 10. The A, B, C, D and E indicate

Table 3. BET surface area and acid site density for selected parameter for sulfonated glucose.

\begin{tabular}{clcccc}
\hline \multirow{2}{*}{ Catalyst } & ICG Preparations & $\begin{array}{c}\text { Sulfonation } \\
\text { time (min) }\end{array}$ & $\begin{array}{c}\text { Surface area } \\
\left(\mathrm{m}^{2} / \mathrm{g}\right)\end{array}$ & $\begin{array}{c}\text { Acid sites } \\
\text { densityb } \\
(\mathrm{mmol} / \mathrm{g})\end{array}$ & Yield (\%) \\
\hline $\mathrm{A}$ & 15 minutes; 20 g D(+)-glucose; Medium & 7 & $9.32 \pm 0.30$ & 25.31 & 86.72 \\
$\mathrm{~B}$ & 20 minutes; $30 \mathrm{~g}$ D(+)-glucose; Medium & 7 & $4.78 \pm 0.40$ & 23.85 & 79.27 \\
$\mathrm{C}$ & 20 minutes; 20 g D(+)-glucose; Low & 7 & $2.03 \pm 0.30$ & 12.93 & 59.22 \\
$\mathrm{D}$ & 20 minutes; 20 g D(+)-glucose; Medium & 7 & $16.94 \pm 0.30$ & 25.65 & 91.41 \\
$\mathrm{E}$ & 20 minutes; 20 g D(+)-glucose; Medium Low & 7 & $2.39 \pm 0.20$ & 17.52 & 69.68 \\
\hline
\end{tabular}

a BET analysis; b TPD- $\mathrm{NH}_{3}$ analysis 
the ammonia desorption curves for various ranges of mass of $\mathrm{D}(+)$-glucose used, heating time for carbonization as well as power level used. Catalyst D prepared using $20 \mathrm{~g}$ of $\mathrm{D}(+)$ glucose and heated for 20 minutes using medium power level shows a sharp peak at $330{ }^{\circ} \mathrm{C}$ within $250{ }^{\circ} \mathrm{C}$ to $400{ }^{\circ} \mathrm{C}$ which is basically appointed as the strong acid sites with 25.65 $\mathrm{mmol} / \mathrm{g}$ density as presented in Table 3 . A weak desorption peak can be observed at $250{ }^{\circ} \mathrm{C}$ within $230-270{ }^{\circ} \mathrm{C}$. This is due to the contact of $-\mathrm{NH}_{3}$ with incomplete carbon sheets as well as the interaction with the $-\mathrm{SO}_{3} \mathrm{H}$ [42]. Catalyst C however displays a broad peak at $350{ }^{\circ} \mathrm{C}$ and

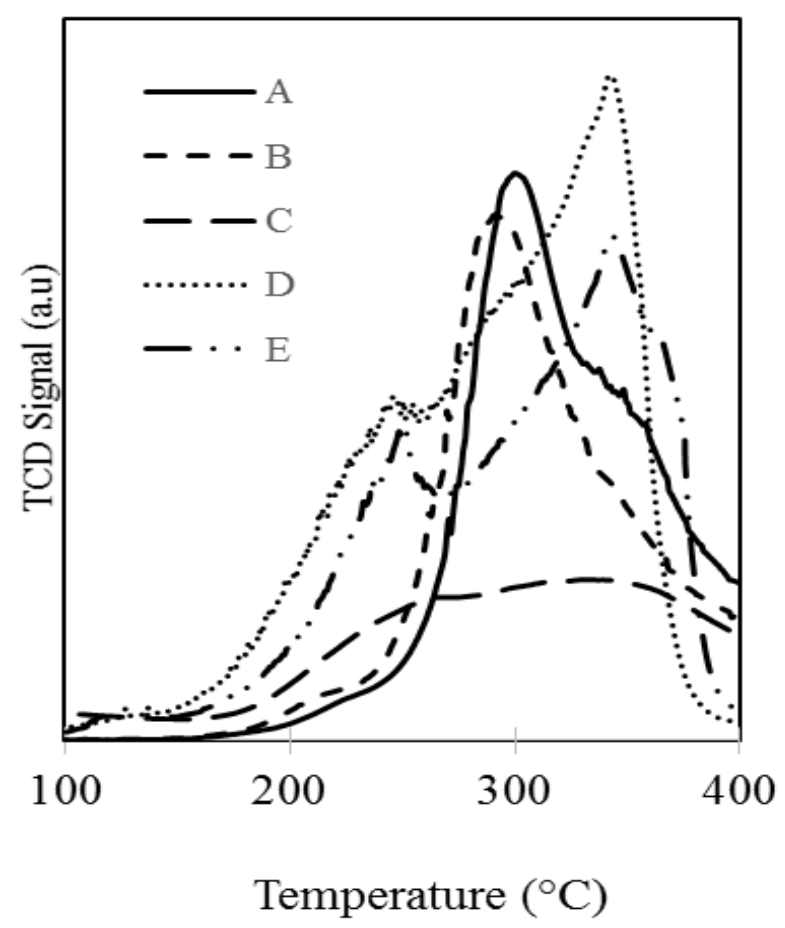

Figure 10. TPD- $\mathrm{NH}_{3}$ for sulfonated glucose A (20 g D(+)-glucose; 15 minutes; Medium), B (30 g D(+)-glucose; 20 minutes; Medium), C (20 g D(+)-glucose; 20 minutes; Low), D (20 g $\mathrm{D}(+)$-glucose; 20 minutes; Medium) and E (20 g D(+)-glucose; 20 minutes; Medium Low).
$500{ }^{\circ} \mathrm{C}$ with lowest desorption of ammonia of $12.93 \mathrm{mmol} / \mathrm{g}$ acid site density. Peaks at high and low temperatures are referred to strong and weak acid sites, respectively. The catalysts were prepared at different power levels indicating different temperatures. The development of the carbon sheet will basically increase with the rise of the temperature or power level during carbonization [43]. However the microwave power level should not be too high since high radiation of the microwave exhibits accumulated discontinuities thus shortening the molecular orientation and vibration [44].

The FAME obtained was then confirmed by went through several test from Laboratory Services Unit (UNIPEM) and the test reported was tabulated in Table 4 . The test report of FAME shows satisfactory result of the FAME's properties including the kinematic viscosity, density, specific gravity, API, pour point, water content as well as flash point.

\subsection{Turnover Frequency (TOF)}

Turnover Frequency (TOF) can be defined as the catalyst activity corresponding to the amount of product obtained per unit time [45]. Figure 11 illustrates the TOF for respective components of FAME consisting of methyl palmitate $\left(\mathrm{C}_{17} \mathrm{H}_{34} \mathrm{O}_{2}\right)$, methyl oleate $\left(\mathrm{C}_{19} \mathrm{H}_{36} \mathrm{O}_{2}\right)$, methyl myristate $\left(\mathrm{C}_{15} \mathrm{H}_{30} \mathrm{O}_{2}\right)$, methyl linoleate $\left(\mathrm{C}_{19} \mathrm{H}_{34} \mathrm{O}_{2}\right)$ and methyl stearate $\left(\mathrm{C}_{19} \mathrm{H}_{38} \mathrm{O}_{2}\right)$. This TOF was taken between 5 to 15 minutes. TOF of methyl palmitate for catalyst D and A were significantly greater than the TOF of other components of FAME. This strongly points out that high FAME yield produced using catalyst D and A were mostly contributed by methyl palmitate formation with TOF of $25.214 \times 10^{-3} \mathrm{~s}^{-1}$ and $18.499 \times 10^{-3} \mathrm{~s}^{-1}$, respectively. As observed, the TOF for methyl linoleate and methyl myristate were almost negligible since their TOF were below $1 \mathrm{~s}^{-1}$. Catalyst D produced more methyl ester compared to other catalysts. From BET results, it is confirmed

Table 4. Test report for fatty acid methyl ester.

\begin{tabular}{llcc}
\hline No & Parameters, units & Results & Test Method \\
\hline 1 & Kinematic Viscosity @ $40^{\circ} \mathrm{C}, \mathrm{cSt}$ & 5.36 & ASTM D445-94 \\
2 & Density @ $15^{\circ} \mathrm{C}, \mathrm{kg} / \mathrm{L6}$ & 878.9 & ASTM D1298-85(90) \\
3 & Specific Gravity @ 60/60 $\mathrm{F}$ & 0.87933 & ASTM D1298-85(90) \\
4 & ${ }^{\circ}$ API & 29.35 & ASTM D1298-85(90) \\
5 & Pour Point & 12 & ASTM D97-93 \\
6 & Water Content (by distillation), \% wt & 0.15 & ASTM D95-83 \\
7 & Flash Point (COC), ${ }^{\circ} \mathrm{C}$ & 188 & ASTM D92-90 \\
\hline
\end{tabular}


that catalyst $\mathrm{D}$ produced higher surface area compared to the rest of the catalysts. Lower TOF can be influenced by too low or too high carbonization or sulfonation temperature used during preparation of the catalyst in microwave. Low or high temperature or power level of the microwave disfavors the functionalization of the sulfonic groups [36]. The result shows that the content of the sulfonic group is the most important component in esterification reaction due to its high acid strength [46].

\subsection{Regeneration of Sulfonated Glucose Cata- lyst on Esterification Process}

Regeneration test was conducted to investigate the stability of the catalyst since it is an important element especially in industrial processes. The test was carried out using 10:1 molar ratio of methanol to $\mathrm{PFAD}, 75^{\circ} \mathrm{C}$ of temperature, $2.5 \mathrm{wt} \%$ of catalyst loading for 2 hours of reaction time. The catalyst was separated from the mixture, washed using hot distilled water and dried before it went through the next catalytic reaction under the same operating condition. Figure 12 represents the regeneration of the sulfonated glucose catalyst prepared at 20 minutes heating time, $20 \mathrm{~g} \mathrm{D}(+)$-glucose using medium power level of microwave. 6 cycles under the same operating condition was reached with $70.37 \%$ yield. The prepared catalyst was able to convert $90.61 \%$ of the PFAD to FAME and reduced to $80.04 \%, 75.92 \%, 70.41 \%$ for the second, third and fourth run, respectively. Slight reduction of conversion percentage and stable activity were resulted in for the fifth and sixth consecutive run. This is due to the deactivation or leaching of the active sites of the sulfonated glucose [47]. Leaching defines that the supporting material is partially detached from the usual coordinative and not covalently bonded catalyst when specific solvent is employed [48]. The noticeable reduction of yield and conversion percentage demonstrates lower regeneration of the prepared catalyst, which highly is attributed to the hydrophilicity of the $\mathrm{SO}_{3} \mathrm{H} / \mathrm{ICG}$. Lokman et al. [20] used sulfonated glucose via conventional method and managed to convert $81.5 \%$ of FFA and $73.4 \%$ of yield up until 6 cycles. Chin and colleagues reported on

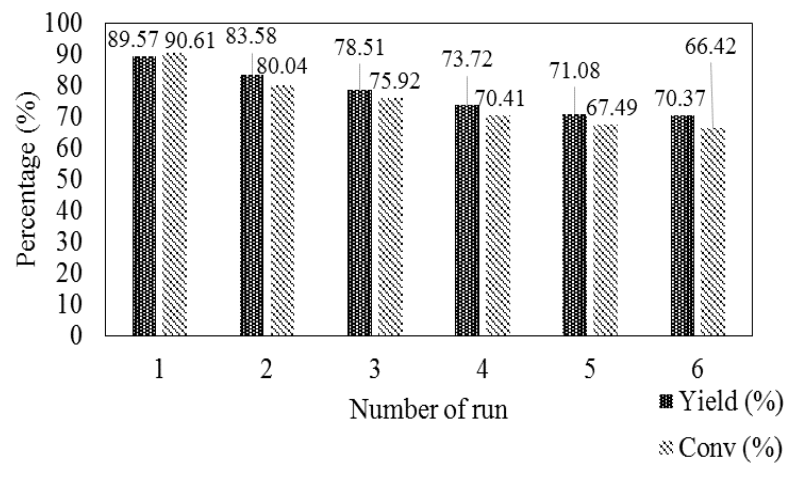

Figure 12. Regeneration of sulfonated glucose prepared under microwave-assisted method.

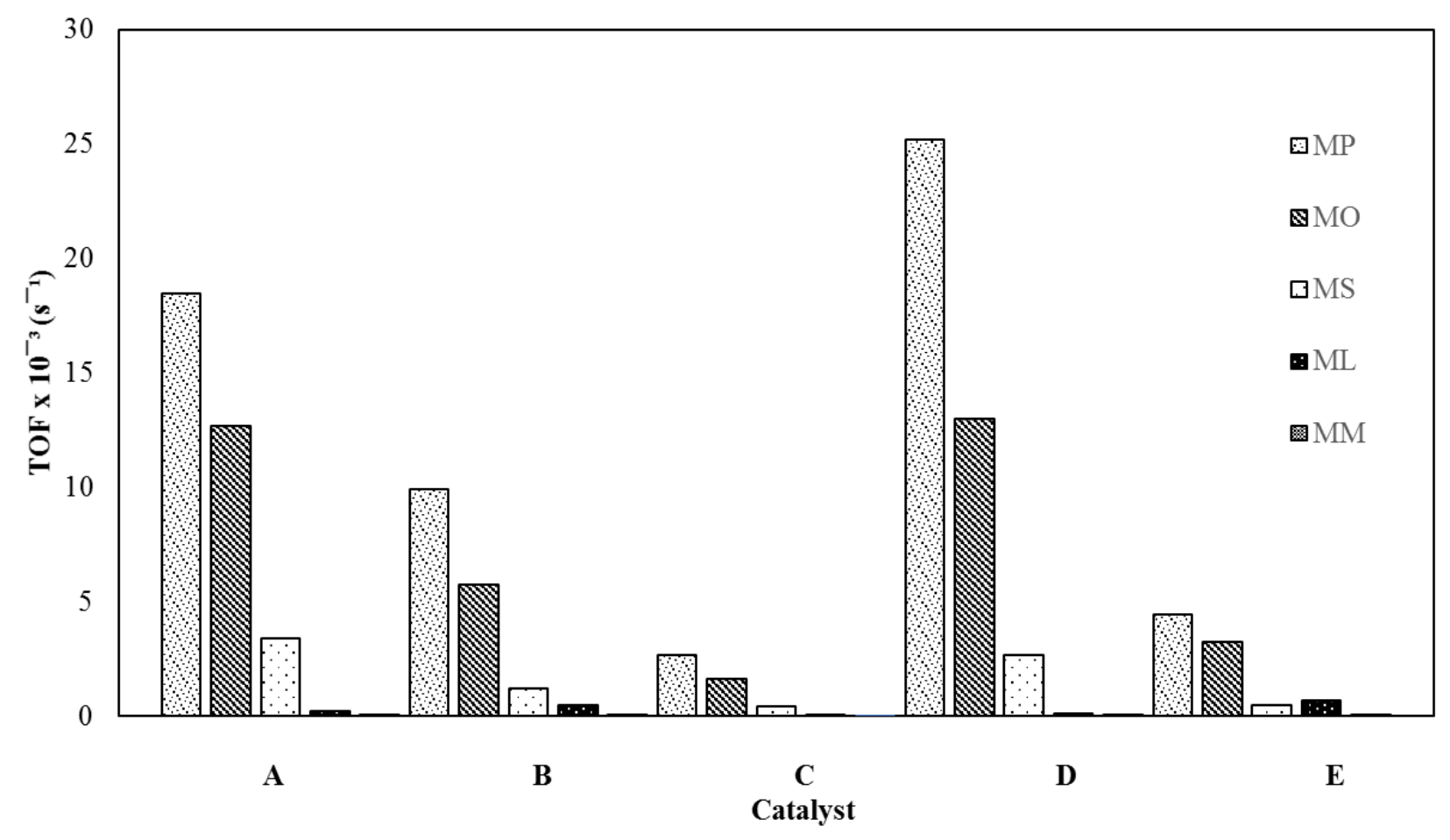

Figure 11. Turnover frequency of sulfonated glucose acid catalysts A, B, C, D and E. 
the regeneration of sulfonated sugar cane bagasse as acid catalyst prepared via conventional heating method to produce methyl ester. Their catalyst activity was reduced to $15 \%$ even after 5 cycle of reaction and produced $65 \%$ of methyl ester content at 20:1 molar ratio of methanol to $\mathrm{PFAD}, 170{ }^{\circ} \mathrm{C}, 30$ minutes of reaction time with $11.5 \mathrm{wt} \%$ of the prepared catalyst [49].

\subsection{Reaction Mechanism}

PFAD consists of fatty acids which can be esterified efficiently with the existence of the alcohol and acid catalyst. This system is under two-phase system consisting of two immiscible liquid phases (PFAD and methanol) as well as a solid (heterogeneous acid catalyst). In order to determine the rate-limiting step, a comparison between rates of the different elementary steps should be performed. Most researchers used either the Eley-Rideal (ER) or LangmuirHinshelwood-Hougen-Watson (LHHW) methods. Jamal and colleagues used both method of ER and LHHW for transesterification of soybean oil on Amberlyst A26-OH basic ionexchange resin with and without free fatty acids [50]. Four steps of mechanism is proposed including methanol adsorption by ion exchange on basic resin surface, fatty acid adsorption by ion exchange on basic resin surface, hydrolysis of tri-, di- and monoglycerides from soybean oil and last one the transesterification of tri-, diand monoglycerides with basic resin surfacebound methoxide. ER model provide a better description for the interactions of the surface on the resin occur [50].

Many researchers developed its kinetic models based on the first order rate law. Tasić using calcium-based catalyst, $\mathrm{CaO}, \mathrm{Ca}(\mathrm{OH})_{2}$ and $\mathrm{CaO}-\mathrm{ZnO}$ for methanolysis of sunflower oil [51]. The chemical kinetics of the reaction was

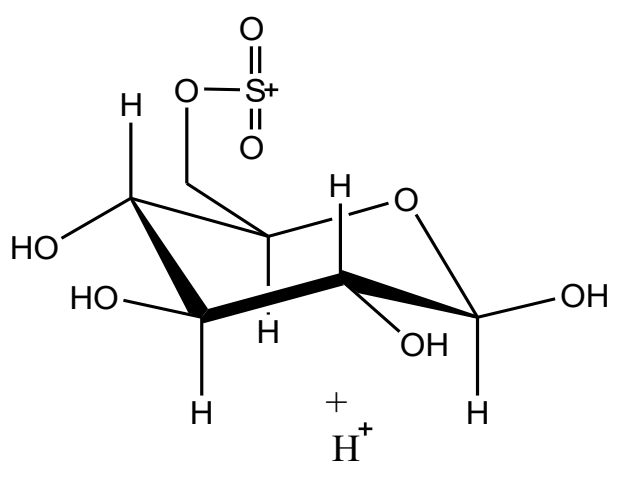<smiles></smiles>

Protonation

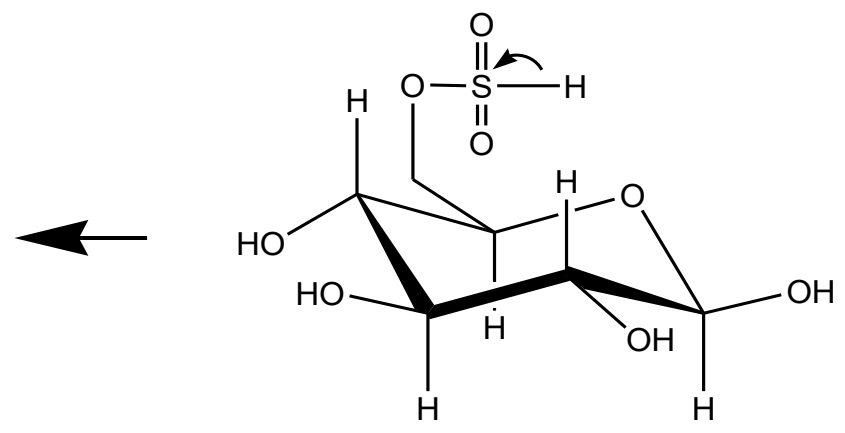

Sulfonated glucose<smiles>[R]C(=O)OC</smiles><smiles>[R]C(OC)=[O+][CH-]</smiles><smiles>[R][C@]1(O)[C@@H](O)CCC[C@H](C)[C@H]1C</smiles><smiles>[R]C(O)(O)[O+](C)OCCC</smiles>

Methyl ester

Figure 13. Proposed mechanism of esterification of PFAD with methanol using sulfonated glucose catalyst. 
adapted from Miladinović which is few assumption made including the methoxide ions are adsorbed on the active centres and react with the liquid phase of triglycerides located closed to the active centres [52]. First order reaction rate with respect to triglycerides and $\mathrm{s}$ is used by Miladinović. Methanolysis of sunflower seed oil has also been studied by Stamenković at temperature of $60{ }^{\circ} \mathrm{C}$ with molar ratio of methanol to oil 6:1 with different amount of $\mathrm{Ca}(\mathrm{OH})_{2}$ loading [53]. Pseudo first-order reaction kinetic model was proposed by Stamenković related with the triglycerides mass transfer limitations. The mass transfer was associated with the drop size of the dispersed (methanol) phase, which reduced rapidly with the progress of the methanolysis reaction. These three examples show the kinetics of methanolysis of sunflower oil is modelled using two stages including initial triglycerides mass transfer limitations and chemically control region.

Figure 13 shows the reaction mechanism of the esterification of PFAD and methanol with the existence of an acid catalyst. Protonation is the first step of the reaction occurred through an esterification process. Mechanistically, $\mathrm{OH}$ is tempted to be protonated however; carbonyl oxygen will be protonated first due to the most nucleophilic site tendency. After the protonation of the carbonyl, some of the electron density will be absorbed by the $\mathrm{O}-\mathrm{H}$ bond formed mainly to donate to the carbonyl carbon group. The protonation thus weaken the carbonoxygen $\pi$ bond which creates the carbonyl carbon as a stronger electrophile. At this stage, any presence of nucleophiles such as the alcohol will develop a quick reaction of the solution.

Methanol in the other hand is a pretty weak nucleophile. A nucleophile which creates a reversible protonation under the reaction condition is preferred for a reaction involving an acid catalyst. For instance, if an amine is used instead of methanol in this esterification process,

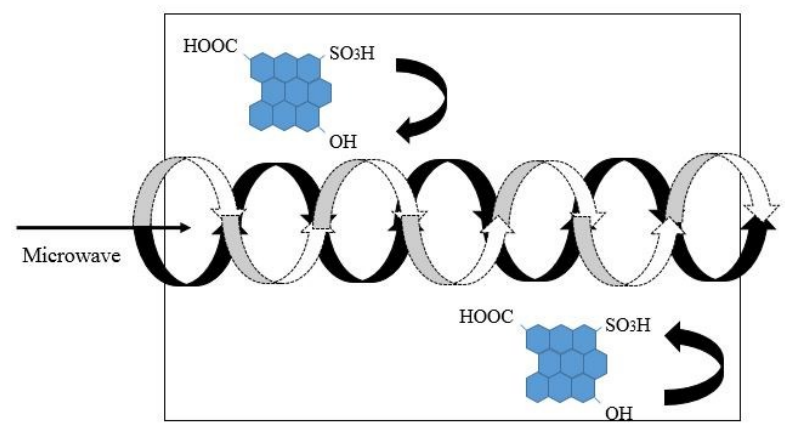

Figure 14. Oscillating electric field, $E$ (uniform heating) in a microwave. there will be no reaction at the carbonyl since the acid reversibly hits the nucleophiles' lone pairs instead of the carbonyl oxygen. 3 carbonoxygen bonds are left after the alcohol attacks. The hydroxyl ion, $\mathrm{OH}^{-}$, will leave under most circumstances because it is easier for $\mathrm{OH}$ to be protonated by $\mathrm{OH}_{2}$ thus leaving as a water group and methyl ester as the end product.

Mechanism of heat generation during microwave-material interaction is complex. The electric and magnetic field components of microwave agitate the orientation, position and movement of dipoles, free electrons, domain wall and electron spin during material processing. One or a combination of these phenomena does occur during the interaction. A brief discussion of these heating mechanisms, considering a small volume of materials, is presented in this section. Mechanism of carbon catalyst in microwave heating involves the dipolar loss. The dipolar loss is more effective in dielectric insulator materials in which dipoles are generated when exposed to external electric field. The oscillation electric field creates agitation of the molecular dipoles during sulfonation of $\mathrm{SO}_{3} \mathrm{H} / \mathrm{ICG}$ catalyst is shown in Figure 14. The figures illustrates how the molecular dipoles of $\mathrm{SO}_{3} \mathrm{H} / \mathrm{ICG}$ inside the microwave with positive and negative polarity reorient themselves in order to be in phase with the oscillating electric field, $E$. Inertial, elastic frictional and molecular interaction forces resist these frequent changes in orientations of molecules which increase molecular kinetic energy and result in volumetric heating [54]. The kinetic energy increase of all dipoles in the material increases the temperature of the material within a short time [55].

\subsection{Pseudo Second Order of Esterification of PFAD}

The difference of reaction temperature $\left({ }^{\circ} \mathrm{C}\right)$, molar ratio of methanol to $\mathrm{PFAD}$ and weight catalyst (wt\%) in PFAD esterification using $\mathrm{SO}_{3} \mathrm{H} / \mathrm{ICG}$ were used to clarify the kinetic study. The experimental work was designed as in sub section 2.6. The important element while calculating the reaction rate constants with different temperatures, molar ratio of PFAD to methanol, as well as the catalyst loading is the conversion percentage of PFAD in equilibrium state $\left(x_{e}\right)$. In this study, the equilibrium conversion can be determined through a 24 hour continuous PFAD esterification at 65 ${ }^{\circ} \mathrm{C}, 75^{\circ} \mathrm{C}$ and $85^{\circ} \mathrm{C}$. Based on the batch esterification, a maximum 0.95 of conversion can be reached even though the reaction time is fur- 
ther increase to a certain value. Thus, the $x_{e}$ of PFAD is 0.95 at 65,75 , and $85^{\circ} \mathrm{C}$.

Equation (25) can be compared with $y=m x+c$ and $k_{1}$ value can be determined by the slope of the graph $\ln [x+(1+b+\theta) / 2 a] /[x-(b-1-\theta) / 2 a]$ against time $(t)$ as plotted in Figure 15, Figure 16 and Figure 17. Each figures representing the different temperatures $\left(65,75\right.$, and $\left.85{ }^{\circ} \mathrm{C}\right)$ molar ratios $(5: 1,10: 1$ and $15: 1)$ and catalyst loading ( $1 \mathrm{wt} \%, 2.5 \mathrm{wt} \%$ and $4 \mathrm{wt} \%)$ in esterification of PFAD using $\mathrm{SO}_{3} \mathrm{H} / \mathrm{ICG}$. Based on these graph, it can be observed that the experimental data points narrowly scattered with the linear fit data. This is a proof that the experimental and calculated values particularly have a good agreement between each other.

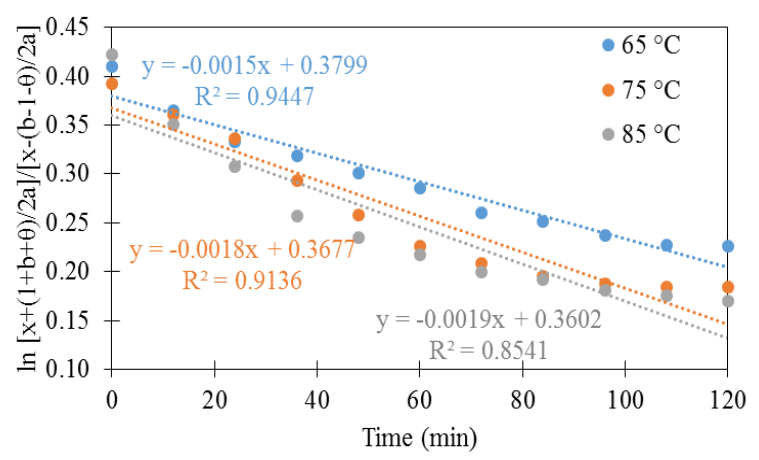

Figure 15. Graph of $\ln ((x+(b+11) / 2 a) /(x-(b-$ $11) / 2 a)$ ) against time (min) at different temperatures.

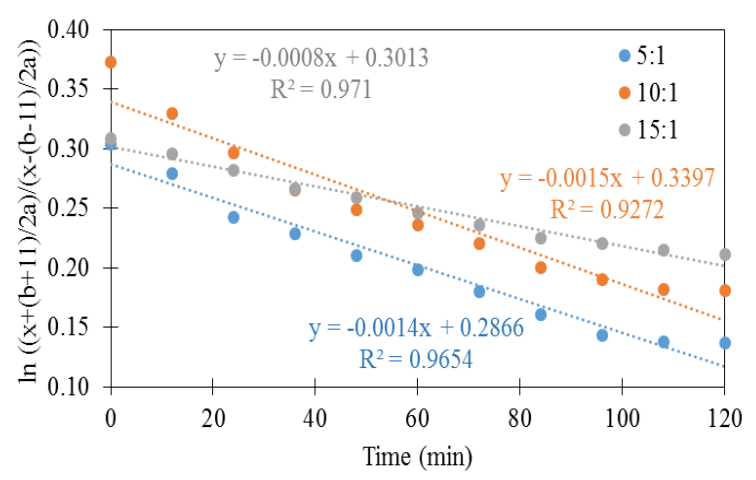

Figure 16. Graph of $\ln ((x+(b+11) / 2 a) /(x-(b-$ $11) / 2 a)$ ) against time (min) at different molar ratios.
Value of $a, b$, rate constants of forward $\left(k_{1}\right)$ and reverse $\left(k_{2}\right)$ as well as the linearity dependent coefficients $\left(\mathrm{R}^{2}\right)$ under different reaction temperature $\left({ }^{\circ} \mathrm{C}\right)$, molar ratio of methanol to PFAD and catalyst loading (wt\%) are tabulated in Tables 5, 6, and 7, respectively. The $\mathrm{R}^{2}$ value measures the percentage of variation of the y-axis which can be attributed to the variation of x-axis. Most of the $\mathrm{R}^{2}$ from the tables show above 0.90 which indicates above $90 \%$ of the variation of the $\ln [x+(1+b+\theta) / 2 a] /[x-(b-1$ $\theta) / 2 a]$ is due to the variation of the time ( $\mathrm{min}$ ).

The kinetic model proposed in this study defines the experimental results well. Table 5 shows that the rate constants increased with the increment of the temperature $\left(65\right.$ to $\left.85^{\circ} \mathrm{C}\right)$. Reaction temperature is one of the factors which contribute in the collision frequency. An increment of the temperature will lead to the increment of average velocity of the particles. The average kinetic energy of these particles will as well increase. Subsequently the particles of the reactants will encounter each other frequently. The more particles collide with each other, the more effective collision can occur when the right amount of energy required is consumed. Reaction rate constant tabulated in Table 6 declines with the increment of the molar ratio of methanol to PFAD. The high amount of methanol causing the active sites to be filled by methanol molecule compared to PFAD, thus avoiding the PFAD molecule to be

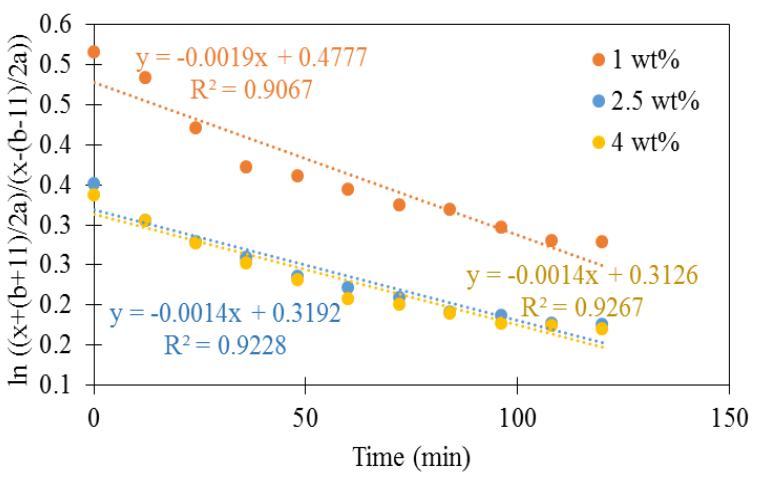

Figure 17. Graph of $\ln ((x+(b+11) / 2 a) /(x-(b-$ $11) / 2 a)$ ) against time (min) at different catalyst loading (wt\%).

Table 5. Value of $a, b$, the rate constant of forward $\left(k_{1}\right)$ and reverse $\left(k_{2}\right)$ reactions as well as the $\mathrm{R}^{2}$ under different temperatures.

\begin{tabular}{cccccc}
\hline Temperature $\left({ }^{\circ} \mathrm{C}\right)$ & $a$ & $b$ & $k_{1}$ & $k_{2}$ & $\mathrm{R}^{2}$ \\
\hline 65 & 0.49861 & 9.00309 & 0.2533073 & 1.84296 & 0.9447 \\
75 & 0.49861 & 9.00309 & 0.0303969 & 1.75155 & 0.9136 \\
85 & 0.49861 & 9.00309 & 0.0320856 & 1.72444 & 0.8541 \\
\hline
\end{tabular}


protonated at the active sites.

The rate constant of different weight of catalyst loading in the other hand shows an increment from $1 \mathrm{wt} \%$ to $2.5 \mathrm{wt} \%$. However, a constant $\mathrm{k}_{1}$ and $\mathrm{k}_{2}$ are observed when the catalyst loading is further increased to $4 \mathrm{wt} \%$. Similar result was obtained by Pisarello, where the increment of $\mathrm{k}$ value was observed when the homogeneous acid catalyst concentration was increased and fitted in second order reverse reaction for esterification of sunflower oil into FAME [56]. High catalyst loading is basically hindering the progress of the reaction due to the increment of the mass transfer resistance. Catalyst in heterogeneous system is basically in solid phase, different phase from the reactants. The catalyst plays a role where they will be embedded into the reacting species which is in liquid phase. Thus, the reaction rate is principally relied on the mass transfer or diffusion between these phases [57]. The reaction rate in heterogeneous system usually decreases due to

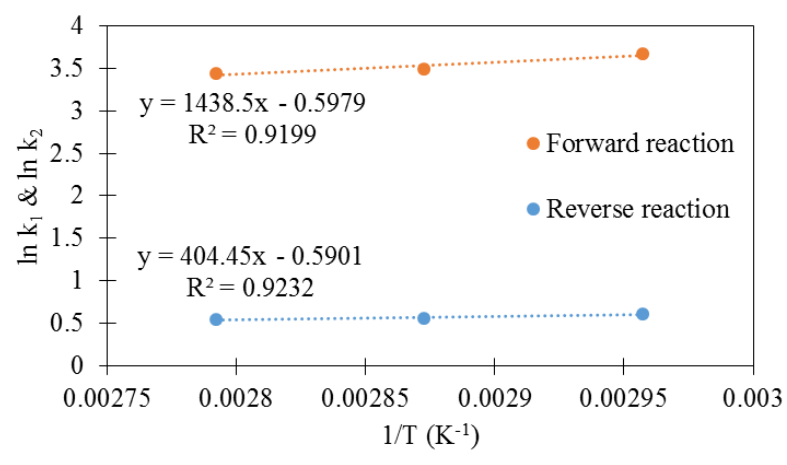

Figure 18. Graph of $\ln k_{1}$ and $\ln k_{2}$ against $1 / \mathrm{T}\left(\mathrm{K}^{-1}\right)$ of esterification of PFAD using $\mathrm{SO}_{3} \mathrm{H} / \mathrm{ICG}$. the catalyst deactivation. Catalyst can be deactivated by several factors including aging, coking or poisoning. Sometimes the products or by-products can plugged into the catalyst pores thus, limiting the mass transfer process from external pore mouth to the internal catalyst surface [57]. Mass transfer limitations were important when small amounts of catalyst were used. However, significant agglomeration of catalyst particles occasioned the limitation of TG mass transfer when the catalyst was used in a greater amounts [53].

Arrhenius equation is used to determine the activation energy $\left(E_{a}\right)$ and pre-exponential factor $(A)$ after the rate constant at different temperatures is calculated. Figure 18 represented the graph of $\ln k_{1} \& \ln k_{2}$ versus $1 / \mathrm{T}$ which providing the value of slope and intercept. $E_{a}$ and $A$ value can be compared with the slope and in the intercept respectively. $\ln k_{1}$ and $k_{2}$ were linear with the contrary of temperatures describing that the esterification of PFAD using $\mathrm{SO}_{3} \mathrm{H} / \mathrm{ICG}$ follows the Arrhenius equation. $E_{a}$ and $A$ of both forward and reverse reaction were determined as tabulated in the Table 8 . Based on Table 8, the $E_{a}$ value associated with $\mathrm{SO}_{3} \mathrm{H} / \mathrm{ICG}$ catalyst is among the lowest when it was compared with the results of other researchers. This is also a proof that the catalyst provides high catalytic activity towards the esterification reaction. Hence, the $\mathrm{SO}_{3} \mathrm{H} / \mathrm{ICG}$ catalyst can be predicted to have high catalytic performance for esterification reaction due to its relatively low $E_{a}$.

Even though the experimental and calculated values show a good correlation, however the graph of $\ln k_{1}$ and $\ln k_{2}$ against $1 / T\left(\mathrm{~K}^{-1}\right)$ shows

Table 6. Value of $a, b$, the rate constant of forward $\left(k_{1}\right)$ and reverse $\left(k_{2}\right)$ reactions as well as the $\mathrm{R}^{2}$ under different molar ratios.

\begin{tabular}{cccccc}
\hline Molar Ratios MeOH:PFAD & $a$ & $b$ & $k_{1}$ & $k_{2}$ & $\mathrm{R}^{2}$ \\
\hline $5: 1$ & 0.60942 & 6.74526 & 0.03857 & 0.00865 & 0.9654 \\
$10: 1$ & 0.49861 & 9.00309 & 0.02533 & 0.01270 & 0.9272 \\
$15: 1$ & 0.38781 & 9.07662 & 0.01042 & 0.00811 & 0.9710 \\
\hline
\end{tabular}

Table 7. Value of $a, b$, the rate constant of forward $\left(k_{1}\right)$ and reverse $\left(k_{2}\right)$ reactions as well as the $\mathrm{R}^{2}$ under different catalyst loading (wt\%).

\begin{tabular}{cccccc}
\hline Cat Loading (wt\%) & $a$ & $b$ & $k_{1}$ & $k_{2}$ & $\mathrm{R}^{2}$ \\
\hline 1.0 & 0.49861 & 9.00309 & 0.03209 & 0.016087 & 0.9067 \\
2.5 & 0.49861 & 9.00309 & 0.02364 & 0.011854 & 0.9228 \\
4.0 & 0.49861 & 9.00309 & 0.02364 & 0.011854 & 0.9267 \\
\hline
\end{tabular}




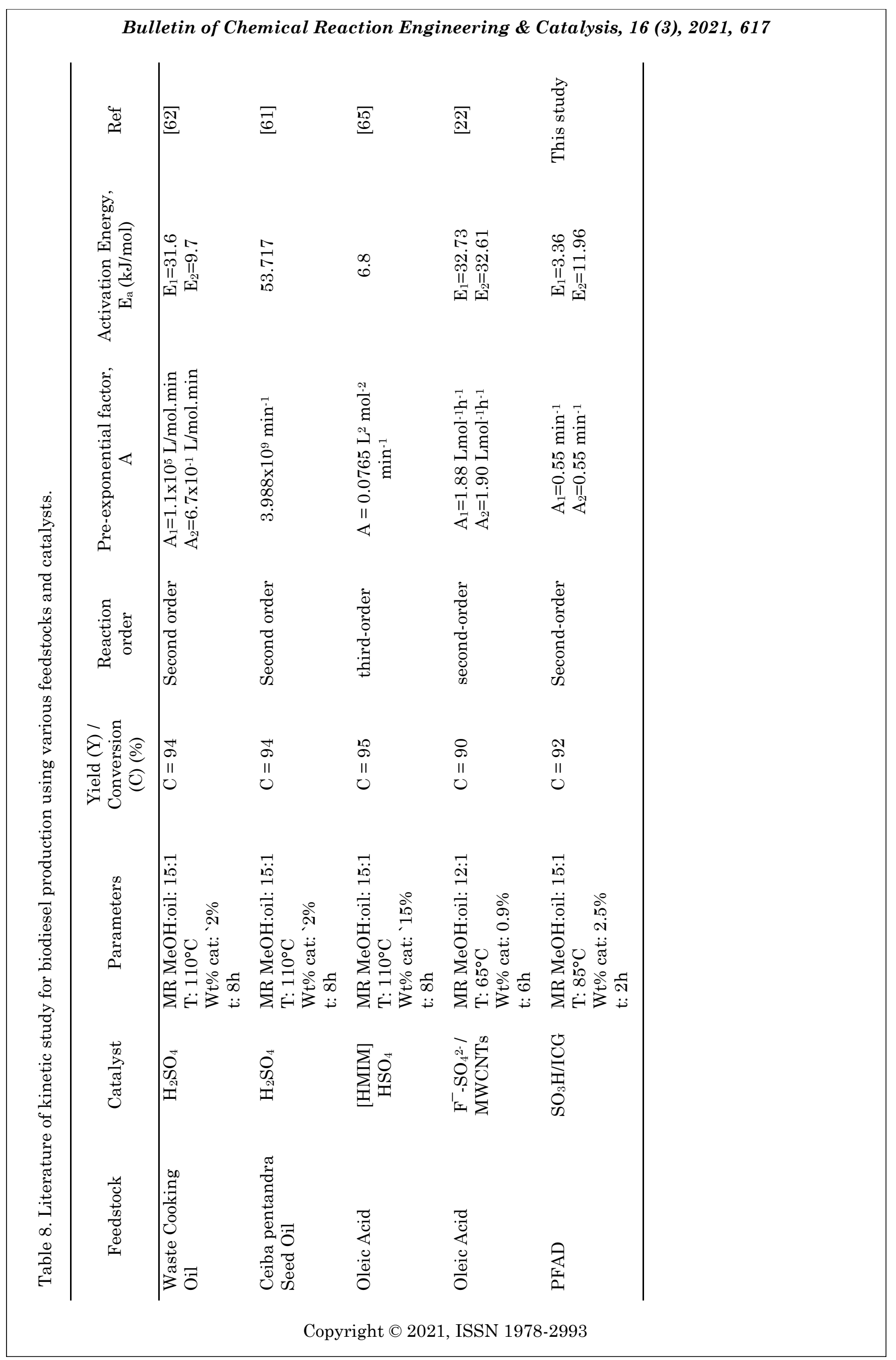


almost a flat line. Considering the smaller value of $\mathrm{R}^{2}$ produced, pseudo first order reaction is the better model for the esterification of PFAD using $\mathrm{SO}_{3} \mathrm{H} / \mathrm{ICG}$ catalyst. Jacob in his thesis as well compared between two reaction kinetics in the transesterification of soybean oil and methanol using the highest $\mathrm{R}^{2}$ provided [58].

Table 8 shows the comparison of the kinetic study of esterification from various feedstocks using acid heterogeneous catalyst. From the table, it can be seen that activation energy of this study is comparable and the lowest among the activation energy from other study. Wang and colleagues obtained the lowest activation energy which is $24.7 \mathrm{~kJ} / \mathrm{mol}$, however, the catalyst prepared took quite a long time since the catalyst is conventionally prepared by sulfonation for $16 \mathrm{~h}$ [59]. Shu and colleagues, however, manages to obtain $E_{a}$ value of $32.7 \mathrm{~kJ} / \mathrm{mol}$ from esterification of oleic acid and $\mathrm{F}^{-}-\mathrm{SO}_{2}{ }^{-4} / \mathrm{MWCNTs}$ catalyst. The catalyst was also prepared in 30 to 60 min at higher temperature which was between 500 to $700{ }^{\circ} \mathrm{C}$ [22]. $\mathrm{Li}$ and colleagues managed to obtain $47.9 \mathrm{~kJ} / \mathrm{mol}$ of the activation energy, a little bit higher than the rest by using rubber seed oil as the feedstock and $\mathrm{SO}_{4}{ }^{2-} / \mathrm{ZrO}_{2}$ as the catalyst which was prepared at $550{ }^{\circ} \mathrm{C}$ for $4 \mathrm{~h} \mathrm{[60].} \mathrm{Lieu} \mathrm{and} \mathrm{col-}$ leagues however obtained the highest activation energy of $53.7 \mathrm{~kJ} / \mathrm{mol}$ using Ceiba pentandra seed oil and $\mathrm{H}_{2} \mathrm{SO}_{4}$ as a catalyst [61]. The esterification of the seed oil was done in a microwave and obtained $94.43 \%$ of FFA conversion. Mazubert and colleagues also study the esterification of waste cooking oil in a microwave using $\mathrm{H}_{2} \mathrm{SO}_{4}$ as a catalyst and obtained $37.1 \mathrm{~kJ} / \mathrm{mol}$ of activation energy [62]. These two studies were proofs that the microwave irradiation is an effective tool for FAME production. Most of the activation energy values in Table 8 are almost analogous with this study, however, the preparation of the catalyst offer significant differences in term of the energy utilization and time consumption. $\mathrm{Xu}$ and colleagues reported that microwaves have an intrinsic catalytic effect, since they allow for the lowering of the apparent activation energy [63]. The authors gave a new interpretation, based on experimental evidence, of the microwaveacceleration of heterogeneous gas-phase catalytic reactions, not only due the presence of "hot-spots". In the field of the organic synthesis, the studies performed allowed concluding that in the reactions characterized by the electron transfer as the main factor, such as the photochemically assisted reactions, the electromagnetic field may have a positive influence (non-thermal effects) since a higher conversion can be obtained using higher microwave power. The case of the reactions where the main factor is the thermal energy is different: in this case, the increase of the microwave power does not result in reaction enhancement since the microwave power delivers an amount of energy smaller than the thermal energy [64].

\section{Conclusions}

Microwave-assisted sulfonated glucose prepared has successfully esterified the PFAD. The best catalyst was prepared using $20 \mathrm{~g}$ $\mathrm{D}(+)$-glucose, heated for 20 minutes by using medium microwave power level, sulfonated using $100 \mathrm{ml} \mathrm{H}_{2} \mathrm{SO}_{4}$ and heated for 7 minutes at medium high power level. The results show remarkable yield of methyl ester produced which was up to $91.41 \%$ at 2 hour reaction time, 2.5 $\mathrm{wt} \%$ catalyst loading, $75{ }^{\circ} \mathrm{C}$ reaction temperature and 10:1 molar ratio of methanol to PFAD. Total surface area and acid site density of the catalyst were $16.94 \mathrm{~m}^{2} / \mathrm{g}$ and $25.65 \mathrm{mmol} / \mathrm{g}$, respectively. The regeneration test indicated 6 cycles of maximum stability. Kinetic study was developed throughout the esterification process and activation energy for forward and reverse reaction were $3.36 \mathrm{~kJ} / \mathrm{mol}$ and $11.96 \mathrm{~kJ} / \mathrm{mol} \mathrm{re}$ spectively. The value is acceptably low compared to other study. In a nut shell, sulfonated glucose acid catalyst prepared via microwave technique showed tremendous potential to esterify feedstock with high FFA at a significantly shorter duration, thus reducing the production cost of FAME.

\section{Acknowledgments}

The authors would like to express gratitude and many thanks for the financial support to conduct this study from Ministry of Education and Universiti Teknologi Malaysia under Vot no. $07 \mathrm{H} 81$ and $12 \mathrm{~J} 43$.

\section{References}

[1] Bauer, N., Bosetti, V., Hamdi-Cherif, M., Kitous, A., McCollum, D., Méjean, A., Rao, S., Turton, H., Paroussos, L., Ashina, S., Calvin, K., Wada, K., Vuuren, D.V. (2015). $\mathrm{CO}_{2}$ emission mitigation and fossil fuel markets: Dynamic and international aspects of climate policies. Technological Forecasting and Social Change, $90,243-256$. D O I : 10.1016/j.techfore.2013.09.009.

[2] Höök, M., Tang, X. (2013). Depletion of fossil fuels and anthropogenic climate change-A review. Energy Policy, 52, 797-809. DOI: 10.1016/j.enpol.2012.10.046. 
[3] Adewale, P., Dumont, M.-J., Ngadi, M. (2015). Recent trends of biodiesel production from animal fat wastes and associated production techniques. Renewable and Sustainable Energy Reviews, 45, 574-588. DOI: 10.1016/j.rser.2015.02.039.

[4] Issariyakul, T., Dalai, A.K. (2014). Biodiesel from vegetable oils. Renewable and Sustainable Energy Reviews, 31, 446-471. DOI: 10.1016/j.rser.2013.11.001.

[5] Phan, A.N., Phan, T.M. (2008). Biodiesel production from waste cooking oils. Fuel, 87, 3490-3496. DOI: 10.1016/j.fuel.2008.07.008.

[6] Malvade, A.V., Satpute, S.T. (2013). Production of Palm Fatty Acid Distillate Biodiesel and Effects of its Blends on Performance of Single Cylinder Diesel Engine. Procedia Engineering, 64, 1485-1494. DOI: 10.1016/j.proeng.2013.09.230.

[7] Lam, M.K., Lee, K.T., Mohamed, A.R. (2010). Homogeneous, heterogeneous and enzymatic catalysis for transesterification of high free fatty acid oil (waste cooking oil) to biodiesel: A review. Biotechnology Advances, 28, 500-518. DOI: 10.1016/j.biotechadv.2010.03.002.

[8] Chai, M., M., Tu, Q., Lu, M., Yang, Y.J. (2014). Esterification pretreatment of free fatty acid in biodiesel production, from laboratory to industry. Fuel Processing Technology,

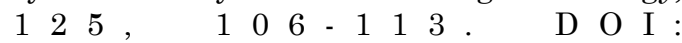
10.1016/j.fuproc.2014.03.025.

[9] Chongkhong, S., Tongurai, C., Chetpattananondh, P., Bunyakan, C. (2007). Biodiesel production by esterification of palm fatty acid distillate. Biomass and Bioenergy, 31, 563568. DOI: 10.1016/j.biombioe.2007.03.001.

[10] Hassan, M.H., Kalam, M.A. (2013). An Overview of Biofuel as a Renewable Energy Source: Development and Challenges. Procedia Engineering, 56, 39-53. DOI: 10.1016/j.proeng.2013.03.087.

[11] Singh, S.P., Singh, D. (2010). Biodiesel production through the use of different sources and characterization of oils and their esters as the substitute of diesel: A review. Renewable and Sustainable Energy Reviews, 14, 200216. DOI: 10.1016/j.rser.2009.07.017.

[12] Leung, D.Y.C., Guo, Y. (2006). Transesterification of neat and used frying oil: Optimization for biodiesel production. Fuel Processing Technology, 87, 883-890. DOI: 10.1016/j.fuproc.2006.06.003.

[13] Lee, A.F., Wilson, K. (2015). Recent developments in heterogeneous catalysis for the sustainable production of biodiesel. Catalysis To$\begin{array}{llrl}d a y, \quad 242, & 3-18 \text {. D O I : }\end{array}$ 10.1016/j.cattod.2014.03.072.
[14] Guldhe, A., Singh, P., Ansari, F.A., Singh, B., Bux, F. (2017). Biodiesel synthesis from microalgal lipids using tungstated zirconia as a heterogeneous acid catalyst and its comparison with homogeneous acid and enzyme catalysts. Fuel, 187, 180-188. DOI: 10.1016/j.fuel.2016.09.053.

[15] Đặng, T.-H., Chen, B-H., Lee, D-J. (2017). Optimization of biodiesel production from transesterification of triolein using zeolite LTA catalysts synthesized from kaolin clay. Journal of the Taiwan Institute of Chemical Engine ers, $\quad 79, \quad 14-22$. D O I : 10.1016/j.jtice.2017.03.009.

[16] Islam, A., Taufiq-Yap, Y.H., Ravindra, P., Teo, S.H., Sivasangar, S., Chan, E-S. (2015). Biodiesel synthesis over millimetric $\mathrm{Y}^{-}$ Al2O3/KI catalyst. Energy, 89, 965-973. DOI: 10.1016/j.energy.2015.06.036.

[17] Glisic, S.B., Orlović, A.M. (2014). Review of biodiesel synthesis from waste oil under elevated pressure and temperature: Phase equilibrium, reaction kinetics, process design and techno-economic study. Renewable and Sustainable Energy Reviews, 31, 708-725. DOI: 10.1016/j.rser.2013.12.003.

[18] Ning, Y., Niu, S. (2017). Preparation and catalytic performance in esterification of a bamboo-based heterogeneous acid catalyst with microwave assistance. Energy Conversion and Management, 153, 446-454. DOI: 10.1016/j.enconman.2017.10.025.

[19] Zahari, M.A.K.M., Zakaria, M.R., Ariffin, H., Mokhtar, M.N., Salihon, J., Shirai, Y., Hassa, M.A. (2012). Renewable sugars from oil palm frond juice as an alternative novel fermentation feedstock for value-added products. Bioresource Technology, 110, 566-571. DOI: 10.1016/j.biortech.2012.01.119.

[20] Lokman, I.M., Rashid, U., Taufiq-Yap, Y.H., Yunus, R. (2015). Methyl ester production from palm fatty acid distillate using sulfonated glucose-derived acid catalyst. Renewable Energy, 81, $347-354$. D O I : 10.1016/j.renene.2015.03.045.

[21] Yu, H., Niu, S., Bai, T., Tang, X., Lu, C. (2018). Microwave-assisted preparation of coal-based heterogeneous acid catalyst and its catalytic performance in esterification. Journal of Cleaner Production, 183, 67-76. DOI: 10.1016/j.jclepro.2018.02.145.

[22] Shu, Q., Zou, W., He, J., Lesmana, H., Zhang, C., Zou, L. (2019). Preparation of the $\mathrm{F}^{-}-\mathrm{SO}_{4}{ }^{2-}$ /MWCNTs catalyst and kinetic studies of the biodiesel production via esterification reaction of oleic acid and methanol. Renewable Energy, 135, 836-845. DOI: 10.1016/j.renene.2018.12.067. 
[23] Funebo, T., Ahrne, L., Kidman, S., Langton, M., Skjoldebrand, C. (2000). Microwave heat treatment of apple before air dehydration effects on physical properties and microstructure. Journal of Food Engineering, 46, 173182. DOI: 10.1016/S0260-8774(00)00080-7.

[24] Chellappan, S., Nair, V., V.S., K.A. (2018). Synthesis, optimization and characterization of biochar based catalyst from sawdust for simultaneous esterification and transesterification. Chinese Journal of Chemical Engineering, 26, 2654-2663. DOI: 10.1016/j.cjche.2018.02.034.

[25] Thushari, I., Babel, S. (2018). Sustainable utilization of waste palm oil and sulfonated carbon catalyst derived from coconut meal residue for biodiesel production. Bioresource Technology. 248, 199-203. DOI: 10.1016/j.biortech.2017.06.106.

[26] Thushari, I., Babel, S. (2018). Preparation of solid acid catalysts from waste biomass and their application for microwave-assisted biodiesel production from waste palm oil. Waste Management \& Research, 36, 719-828. DOI: $10.1177 / 0734242 X 18789821$.

[27] Laohapornchaiphan, J., Smith, C.B., Smith, S.M. (2017). One-step Preparation of Carbonbased Solid Acid Catalyst from Water Hyacinth Leaves for Esterification of Oleic Acid and Dehydration of Xylose. Chem Asian Journal, $12, \quad 3178-3186$. D O I : 10.1002/asia.201701369.

[28] Nda-Umar, U.I., Ramli, I., Muhamad, E.N., Taufiq-Yap, Y.H., Azri, N. (2020). Synthesis and characterization of sulfonated carbon catalysts derived from biomass waste and its evaluation in glycerol acetylation. Biomass Conversion and Biorefinery, 10, 1-16. DOI: 10.1007/s13399-020-00784-0.

[29] Zhou, Y., Niu, S., Li, J. (2016). Activity of the carbon-based heterogeneous acid catalyst derived from bamboo in esterification of oleic acid with ethanol. Energy Conversion and Management, 114, 188-196. DOI: 10.1016/j.enconman.2016.02.027.

[30] Klinger, J.L., Westover, T.L., Emerson, R.M., Williams, C.L., Hernandez, S., Monson, G.D. (2018). Effect of biomass type, heating rate, and sample size on microwave-enhanced fast pyrolysis product yields and qualities. Applied Energy, 228, 535-545. D O : 10.1016/j.apenergy.2018.06.107.

[31] Klinbun, W., Rattanadecho, P. (2012). Analysis of microwave induced natural convection in a single mode cavity (Influence of sample volume, placement, and microwave power level). Applied Mathematical Modelling, 36, 813828. DOI: 10.1016/j.apm.2011.07.003.
[32] Li, M., Chen, D., Zhu, X. (2013). Preparation of solid acid catalyst from rice husk char and its catalytic performance in esterification. Chinese Journal of Catalysis, 34, 1674-1682. DOI: 10.1016/S1872-2067(12)60634-2.

[33] Lokman, I.M., Rashid, U., Taufiq-Yap, Y.H. (2015). Production of biodiesel from palm fatty acid distillate using sulfonated-glucose solid acid catalyst: Characterization and optimization. Chinese Journal of Chemical Engineering, 23, 1857-1864. DOI: 10.1016/j.cjche.2015.07.028.

[34] Li, Z., Raghavan, V.G.S., Orsat, V. (2010). Temperature and power control in microwave drying. Journal of Food Engineering, 97, 478483. DOI: 10.1016/j.jfoodeng.2009.11.004.

[35] Nakajima, K., Hara, M. (2012). Amorphous Carbon with SO3H Groups as a Solid Brønsted Acid Catalyst. ACS Catalysis, 2, 1296-1304. DOI: 10.1021/cs300103k.

[36] Okamura, M., Takagaki, A., Toda, M., Kondo, J.N., Domen, K., Tatsumi, T. (2006). AcidCatalyzed Reactions on Flexible Polycyclic Aromatic Carbon in Amorphous Carbon. Chemistry of Materials, 18, 3039-3045. DOI: 10.1021/cm0605623.

[37] Forzatti, P., Lietti, L. (1999). Catalyst deactivation. Catalysis Today, 52, 165-181. DOI: 10.1016/S0920-5861(99)00074-7.

[38] Zainol, M.M., Amin, N.A.S., Asmadi, M. (2017). Effects of thermal treatment on carbon cryogel preparation for catalytic esterification of levulinic acid to ethyl levulinate. Fuel Processing Technology, 167, 431-441. DOI: 10.1016/j.fuproc.2017.07.028.

[39] Lou, W.-Y., Zong, M-H., Duan, Z-Q. (2008). Efficient production of biodiesel from high free fatty acid-containing waste oils using various carbohydrate-derived solid acid catalysts. Bioresource Technology, 99, 8752-8758. DOI: 10.1016/j.biortech.2008.04.038.

[40] Liu, T., Li, Z., Li, W., Shi, C., Wang, Y. (2013). Preparation and characterization of biomass carbon-based solid acid catalyst for the esterification of oleic acid with methanol. Bioresource Technology, 133, 618-621. DOI: 10.1016/j.biortech.2013.01.163.

[41] Touhami, D., Zhu, Z., Balan, W.S., Janaun, J., Haywood, S., Zein, S. (2017). Characterization of rice husk-based catalyst prepared via conventional and microwave carbonisation. Journal of Environmental Chemical Engineering, 5, $388-394$. D O : 10.1016/j.jece.2017.04.020. 
[42] Kastner, J.R., Miller, J., Geller, D.P., Locklin, J., Keith, L.H., Johnson, T. (2012). Catalytic esterification of fatty acids using solid acid catalysts generated from biochar and activated carbon. Catalysis Today, 190, 122-132. DOI: $10.1016 /$ j.cattod.2012.02.006.

[43] Shu, Q., Nawaz, Z., Gao, J.X., Liao, Y.H., Zhang, Q., Wang, D.Z., Wang, J. F. (2010). Synthesis of biodiesel from waste oil feedstocks using a carbon-based solid acid catalyst: Reaction and separation. Bioresource Technology, 101, 5374-5384. DOI: 10.1016/j.biortech.2010.02.050.

[44] Chen, H.-Y., Cui, Z-W. (2016). A MicrowaveSensitive Solid Acid Catalyst Prepared from Sweet Potato via a Simple Method. Catalysts, 6(12), 211. DOI: 10.3390/catal6120211.

[45] Bensebaa, F. (2013). Chapter 5 - Clean Energy. In: F. Bensebaa (Ed) Interface Science and Technology, Elsevier. pp. 279-383. DOI: 10.1016/B978-0-12-369550-5.00005-7.

[46] Aldana-Pérez, A., Lartundo-Rojas, L., Gómez, R., Niño-Gómez, M.E. (2012). Sulfonic groups anchored on mesoporous carbon Starbons-300 and its use for the esterification of oleic acid. Fuel, $\quad 100, \quad 128-138$. D O I : 10.1016/j.fuel.2012.02.025.

[47] Zhang, H., Luo, X., Li, X., Chen, G.Z., He, F., Wu, T. (2016). Preparation and Characterization of a Sulfonated Carbonbased Solid Acid Microspheric Material (SCSAM) and its use for the Esterification of Oleic Acid with Methanol. Austin Chemical Engineering, 3, 1-6. ISSN: 2381-8905.

[48] Gutmann, T., Ratajczyk, T., Xu, Y., Breitzke, H., Grünberg, A., Dillenberger, S. (2010). Understanding the leaching properties of heterogenized catalysts: A combined solid-state and PHIP NMR study. Solid State Nuclear Magnetic Resonance, 38, 90-96. DOI: 10.1016/j.ssnmr.2011.03.001.

[49] Chin, L.H., Abdullah, A.Z., Hameed, B.H. (2012). Sugar cane bagasse as solid catalyst for synthesis of methyl esters from palm fatty acid distillate. Chemical Engineering Journal, 183, 104-107. DOI: 10.1016/j.cej.2011.12.028.

[50] Jamal, Y., Rabie, A., Boulanger, B. (2015). Determination of methanolysis rate constants for low and high fatty acid oils using heterogeneous surface reaction kinetic models. Reaction Kinetics, Mechanisms and Catalysis, 114, 63-74. DOI: 10.1007/s11144-014-0780-5.

[51] Tasić, M.B., Miladinović, M.R., Stamenković, O.S., Veljković, V.B., Skala, D.U. (2015). Kinetic Modeling of Sunflower Oil Methanolysis Catalyzed by Calcium-Based Catalysts. Chemical Engineering \& Technology, 38, 1550-1556. DOI: 10.1002/ceat.201500076.
[52] Miladinović, M.R., Krstić, J.B., Tasić, M.B., Stamenković, O.S., Veljković, V.B. (2014). A kinetic study of quicklime-catalyzed sunflower oil methanolysis. Chemical Engineering Research and Design, 92, 1740-1752. DOI: 10.1016/j.cherd.2013.11.023.

[53] Stamenković, O., Lazic, M., Veljković, V., Skala, D. (2008). Kinetics of sunflower oil methanolysis at low temperatures. Bioresource technology, 99, 1131-1140. DOI: 10.1016/j.biortech.2007.02.028.

[54] Saltiel, C., Datta, A.K. (1999). Heat and Mass Transfer in Microwave Processing. In $A d$ vances in Heat Transfer, Elsevier. pp. 1-94. DOI: $10.1016 /$ S0065-2717(08)70303-4

[55] Zhang, H., Datta, A.K. (2003). Microwave Power Absorption in Single - and Multiple Item Foods. Food and Bioproducts Processing, 81, 257-265. DO I : $10.1205 / 096030803322438027$.

[56] Pisarello, M.L., Dalla, C.B., Mendow, G., Querini, C.A. (2010). Esterification with ethanol to produce biodiesel from high acidity raw materials: Kinetic studies and analysis of secondary reactions. Fuel Processing Technology, $91, \quad \begin{array}{llllllllll}9 & 0 & 0 & 5 & -1 & 0 & 1 & 4\end{array}$. $\quad$ D O I : 10.1016/j.fuproc.2010.03.001.

[57] Klaewkla, R., Arend, M., Hölderich, W. (2011). A Review of Mass Transfer Controlling the Reaction Rate in Heterogeneous Catalytic Systems. In H. Nakajima (Ed.) Mass Transfer-Advanced Aspects. IntechOpen. pp. 667-684. DOI: 10.5772/22962.

[58] Jacob, I., Clausen, E., Carrier, D.J. (2008). Kinetics determination of soybean oil transesterification in the design of a continuous biodiesel production process. Undergraduate Honors Theses, Biological and Agricultural Engineering, University of Arkansas.

[59] Wang, Y.-T., Fang, Z., Zhang, F. (2019). Esterification of oleic acid to biodiesel catalyzed by a highly acidic carbonaceous catalyst. $\mathrm{Ca}$ talysis Today, 319, 172-181. DOI: 10.1016/S1872-5813(17)30018-X.

[60] Li, L., Yan, B., Li, H., Yu, S., Liu, S., Yu, H. (2018). SO42-/ZrO2 as catalyst for upgrading of pyrolysis oil by esterification. Fuel, 226, 190-194. DOI: 10.1016/j.fuel.2018.04.006.

[61] Lieu, T., Yusup, S., Moniruzzaman, M., (2016). Kinetic study on microwave-assisted esterification of free fatty acids derived from Ceiba pentandra Seed Oil. Bioresource Technology, 211, 248-256. D O : 10.1016/j.biortech.2016.03.105. 
[62] Mazubert, A., Taylor, C., Aubin, J., Poux, M. (2014). Key role of temperature monitoring in interpretation of microwave effect on transesterification and esterification reactions for biodiesel production. Bioresource Technology,
161 ,
$270-279$.
D O I :

10.1016/j.biortech.2014.03.011.

[63] Xu, W., Zhou, J., Su, Z., Ou, Y., You, Z. (2016). Microwave catalytic effect: a new exact reason for microwave-driven heterogeneous gasphase catalytic reactions. Catalysis Science \& Technology, 6, 698-702. DOI: 10.1039/C5CY01802A.
[64] Díaz-Ortiz, Á., Prieto, P., de la Hoz, A. (2019). A Critical Overview on the Effect of Microwave Irradiation in Organic Synthesis. The Chemical Record, 19, 85-97. DOI: 10.1002/tcr.201800059

[65] Roman, F.F., Ribeiro, A.E., Queiroz, A., Lenzi, G.G., Chaves, E.S., Brito, P. (2019). Optimization and kinetic study of biodiesel production through esterification of oleic acid applying ionic liquids as catalysts. Fuel, 239, 1231-1239. DOI: 10.1016/j.fuel.2018.11.087

Selected and Revised Papers from International Conference on Sustainable Energy and Catalysis 2021 (ICSEC 2021) (https://engineering.utm.my/chemicalenergy/icsec2021/) (School of Chemical and Energy Engineering, Faculty of Engineering, Universiti Teknologi Malaysia, 16-17th February 2021) after Peer-reviewed by Scientific Committee of ICSEC 2021 and Peer-Reviewers of Bulletin of Chemical Reaction Engineering \& Catalysis.

Editors (Guest) in this ICSEC 2021 section are Nor Aishah Saidina Amin, Mohd Asmadi Mohammed Yussuf, Salman Raza Naqui, while Editor in Chief is I. Istadi. 